\title{
$k^{2} \ell^{3} k^{4}$ Lai Yunfan*
}

\section{Betrayal through obedience: on the history of the unusual inflectional chain in Siyuewu Khroskyabs}

https://doi.org/10.1515/lingty-2021-2075

Received March 26, 2019; accepted December 3, 2019;

published online $\mathbf{m}$

Abstract: This paper focuses on the verbal inflection chain of Siyuewu Khroskyabs, a Gyalrongic language (Trans-Himalayan). Siyuewu Khroskyabs goes against two general typological tendencies: first, as an SOV language, it shows an overwhelming preference for prefixes, which is rarely reported typologically; second, the inflectional prefixes in the outer slots are older than those in the inner slots, which is the reverse case of most languages. In this paper, I will first identify distinct historical layers within the inflectional prefixes, and then focus on two of the prefixes, $d \partial$ - 'even' and $6 \partial^{-}$' $Q$ ' whose evolutionary pathways are relatively clear. The essential part of the hypotheses is that the prefixes originate from enclitics which could be attached to the end of a preverbal chain, originally loosely attached to the verb stem. The preverbal chain later became tightly attached to the verbal stem and eventually became a part of it as a chain of prefixes. As a result, the original enclitics are reanalysed as prefixes. The integration of preverbal morphemes is responsible for the prefixing preference in Modern Siyuewu Khroskyabs. However, despite this superficial prefixing preference, Siyuewu Khroskyabs underlyingly favours postposed morphemes. By following the general suffixing tendency, this language finally managed to create a typologically rare, overwhelmingly prefixing verbal template.

Keywords: affix order; grammaticalisation; inflectional prefixes; Khroskyabs; prefixing preference; rGyalrongic; Siyuewu; suffixing preference; transHimalayan

*Corresponding author: Lai Yunfan [laii-.wen J.fa:n]] (Cantonese),

[laiY.jyn 1.fan ]] (Mandarin), Department of Linguistic and Cultural Evolution, Max Planck Institute for the Science of Human History, Jena, Germany,

E-mail: khroskyabs@gmail.com 


\section{Introduction}

This paper focuses on the inflectional prefix chain of the Siyuewu dialect of Khroskyabs (Glottolog: siya1242, the language is called ronskæ̂d 'Gyalrong language' in Siyuewu Khroskyabs), a Gyalrongic language of the Trans-Himalayan (or Sino-Tibetan) family, spoken in Sichuan, China. There are around 10,000 native speakers of Khroskyabs (Huang 2007), among which 500 speak the Siyuewu variety. Figure 1 shows the location of the language under study.

Summarising Sun (2000), Jacques et al. (2014), Lai (2017), Jacques et al. (2017) and Gong (2018), the subgrouping of the Gyalrongic group can be illustrated in Figure 2. ${ }^{1}$

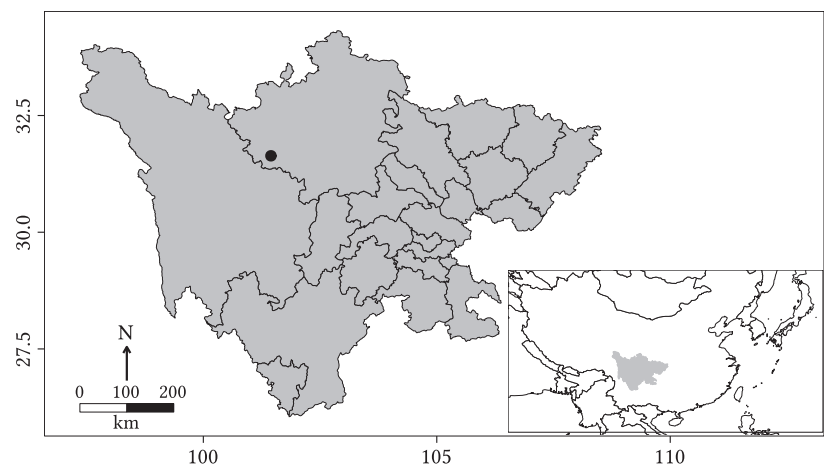

Figure 1: Location of Khroskyabs in Sichuan, China.

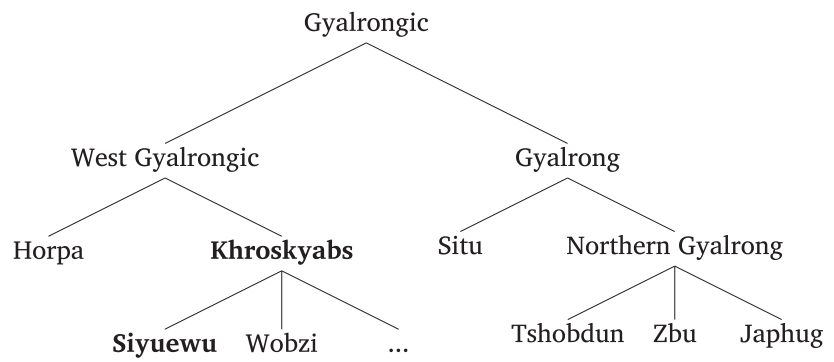

Figure 2: Subgrouping of Gyalrongic.

1 Glottolog codes: Horpa: horp1240, Japhug: japh1234, Tshobdun: tsho1240, Zbu: zbua1234, Situ: situ1238. 
Before examining the case of Siyuewu Khroskyabs, it is necessary to mention two typological trends, the suffixing preference and the correlation between affix age and position.

\subsection{The suffixing preference}

A century ago, Sapir (1921: 67) claimed that the suffixing preference was a "fair guess" concerning the affixal behaviour of a language. Greenberg (1957: 93) noticed that it was easier for a prefixing language to become a suffixing one than the other way around, and that suffixing tended to persist. Based on quantitative analyses, Greenberg (1963: 62, 73) put forward universals on the correlations between syntax and morphology, among which the most relevant to us are:

1. Universal 4: With overwhelmingly greater than chance frequency, languages with normal SOV order are postpositional.

2. Universal 27: If a language is exclusively suffixing, it is postpositional; if it is exclusively prefixing, it is prepositional.

Later observations on the suffixing preference are numerous, such as Bybee et al. (1990), Cysouw (2009), and Dryer (2013). In Dryer's (2013) sample of 894 languages, only $16 \%$ present at least a moderate preference for prefixing, as opposed to to more than $55 \%$ of languages with a suffixing preference.

A number of explanations have been proposed for this preference in the literature. From a psycholinguistic perspective, Hawkins and Cutler (1988) claim that stems and affixes are processed separately with priority on stems, and hence the preference for stems to precede affixes. Prosody is believed to play a role in the emergence of suffixes rather than prefixes, discussed in Himmelmann (2014) who, instead of searching for psycholinguistic explanations, argues that functional words are more frequently placed before phonological boundaries, despite the fact that they may modify the following word. Another line of argument to explain the tendency involves diachrony. Based on the fact that affixes are usually derived from words, Givón (1979) proposes that affix order should reflect the original order of words. This principle can account for the ordering of recently grammaticalised affixes with transparent origins, but it may fail with languages that have already undergone complex morphological changes which have blurred the history of the affix ordering. Hall (1988) therefore proposes a combination of diachronic evidence and psycholinguistic factors.

Although exceptions to the suffixing preference are infrequent, they are not negligible in number. A few languages or families that go against the trend include Athapaskan languages (Hoijer 1971, Glottolog: atha1247), Ket (Werner 1997; Vajda 
2017) (Glottolog: kett1243) and Coptic (Grossman and Polis 2015) (Glottolog: copt1239). Mithun (2003) surveys languages with clear preference for prefixes, especially SOV languages that are predicted to exhibit mainly suffixes, most of which either retained historical syntactic orders, or developed prefixes through semantic and frequency factors.

\subsection{Correlation between affix age and position}

Although not addressed specifically in a dedicated publication to my knowledge, there is a general tendency that affixes in inner slots (i.e. closer to the stem) are older than those in outer slots, especially when it comes to an affix chain limited exclusively to one type of affixes, inflectional or derivational. Lehmann (2015: 155) states that outer morphological layers are generally more recent and less grammaticalised. Inkelas (2016: 500) similarly acknowledges that older affixes are closer to the root than new affixes. The observation of Mithun (2000: 237-240) on Iroquoian (Glottolog: iroq1247) languages shows that inner morphology is shared by all varieties in the family, and that a good portion of the inner affixes are cognates. For the periphery of words, however, she shows that each branch exhibits different word-initial and word-final affixes. She concludes that inner morphology is old, dating back to Proto-Iroquoian, and that at least some outer affixes are recently grammaticalised.

Since inner morphology is generally older, it is expected to be morphologically less transparent than outer morphology. As Mithun (2016: 159-160) sees it, component boundaries involving older affixes weaken, and their phonological, syntactic and semantic identities fade before ultimately fusing with their hosts. Bybee (1994: 258) also observes that older derivational affixes will be more tightly fused both semantically and phonologically to their bases, having undergone more sound change and semantic change.

Productivity is closely related to the age of affixes. Older affixes are expected to be less productive (Bybee 1994: 258). Reynolds (2013: 166) also claims that affixes that have become unproductive are generally found closer to the stem, while affixes that have recently become productive are more often found to the outside of other older affixes. ${ }^{2}$

2 One should keep in mind that affixes can more often than not be reordered for different reasons. Affixes may be ordered as a reflection of syntactic structures (c.f. the Mirror Principle of Baker 1985); their ordering can also be motivated by phonological factors, as in Huave (Glottolog: huav1256), analysed by Kim (2010) and among the derivational prefixes in Wobzi variety of Khroskyabs, described in Lai (2017: 73-75). Haspelmath (1993) proposes the historical process of 


\subsection{The betrayal of Khroskyabs}

I will show that the inflectional chain of Siyuewu Khroskyabs goes against both of these general tendencies in that on the one hand, it exhibits an overwhelming prefixing preference; and on the other hand, the older prefixes in the inflectional chain are ordered outside the newer ones.

By analysing the historical layers of the inflectional chain and the grammaticalisation pathways of certain prefixes, I will postulate hypotheses on the establishment of this unusual structure. Section 2 describes the verbal template in Siyuewu Khroskyabs. In Section 3, some relevant morphophonological phenomena found in the Siyuewu inflectional prefixes are presented; and in Section 4, I will analyse the historical layers of the inflectional chain. Section 5 is dedicated to the concrete grammaticalisation pathways of some recently added prefixes, with special focus on da- 'even' and 62 - 'Q', before coming to the conclusion in Section 6.

\section{The prefixing preference of Siyuewu Khroskyabs}

Gyalrongic languages exhibit rich polysynthetic verbal morphology, with affixation the major strategy in word formation. Both prefixes and suffixes are attested, forming templatic morphology (Jacques 2013; Lai 2017; Sun 2014). An overwhelming preference for prefixes is observed in all known Gyalrongic languages: the prefixal chain of each language can contain more than ten prefixes in a row (Gong 2018; Jacques 2013: 197; Jacques et al. 2017; Zhang 2016). This feature is not typologically common, as we have seen in Section 1.

The verbal template in Siyuewu Khroskyabs is shown in Table 1, with a clear prefixing preference. Both inflectional and derivational prefixes are included in the template. Most of the derivational prefixes are valency-changing morphemes, such as the causative prefixes that increase valency, and passive and reflexive prefixes that decrease valency. Only the autobenefactive prefix $N$ - does not change the valency of a base verb, but it does create a new verb with a modified meaning, such as sjê 'to pick up' versus $n$-ts ${ }^{h} j \hat{e}$ (AUTOBEN-pick.up) 'to obtain'.

externalisation of inflection, accounting for the fact that inflectional affixes are usually ordered outside derivational ones.

3 An epenthetic $t$ occurs automatically between $n$ - and $s$-. 


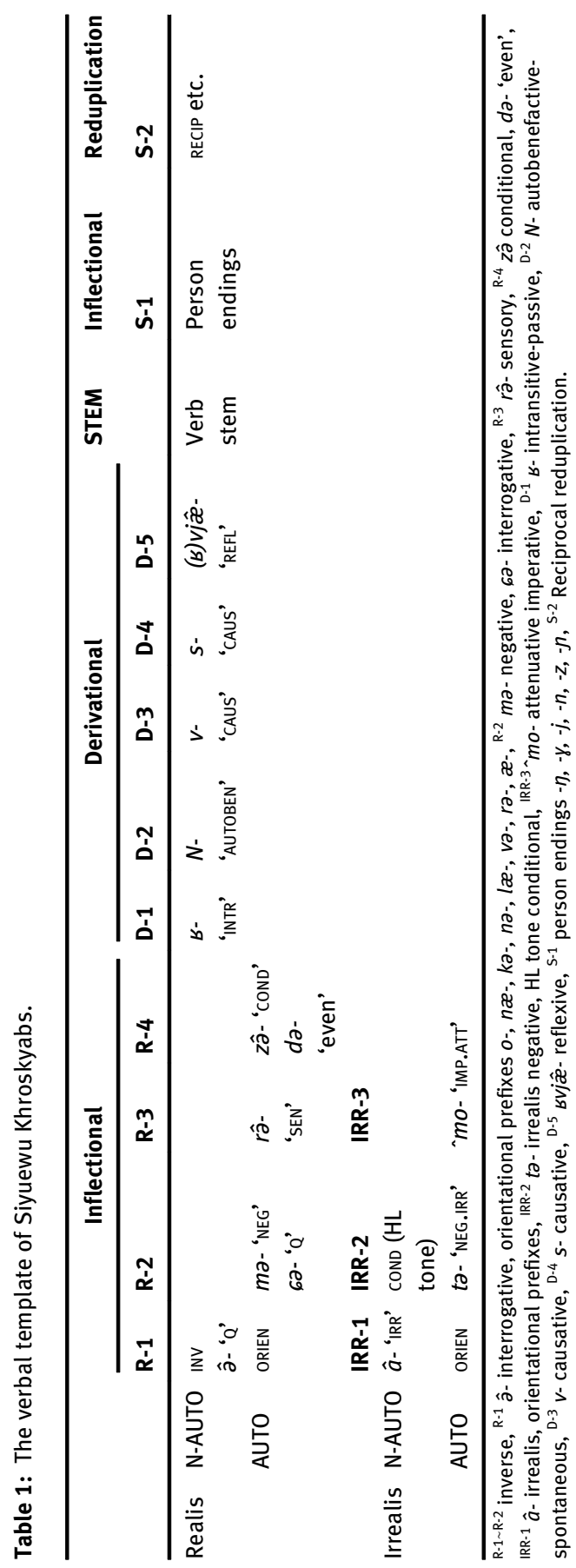


The inflectional prefixes do not change the valency of a verb, nor do they create new verbs. They are divided into two main modal categories, realis and irrealis, and each category into two subcategories, non-autonomous and autonomous. The main categories are presented in overlapped rows, meaning prefixes in one main category cannot appear in the other, except when specifically indicated (for example, the orientational prefixes).

Autonomous prefixes have full-fledged syllabic structures, and have the ability to host non-autonomous prefixes. Non-autonomous markers can only appear in the presence of a pertinent autonomous prefix with which they undergo fusion, indicated by the range in the table (see Section 3.2 for a detailed description).

Some autonomous prefixes, such as $6 \partial-$ 'Q', $z \hat{\partial}$, 'COND', $t \partial-$ 'NEG.IRR', 'mo- 'IMP.ATT' and do- 'even', cannot exist word-initially, and have to be preceded by orientational prefixes. In this sense, they are less autonomous than those prefixes that can exist word-initially, however, they are still termed "autonomous" in this paper for the sake of convenience (see Sections 3.1.2, 3.1.3, 3.3.1, 3.3.2, and 3.3.3 for a more detailed discussion).

The only two types of prefixes that can occur at the beginning of a verb form are the orientational prefixes (Section 3.1.1) and the negative prefix mo(Section 3.1.2). ${ }^{4}$

The ordering of inflectional and derivational categories follows the typological tendency that the inflectional prefixes are placed outside the derivational ones, which could possibly be the result of an externalisation of inflection (Haspelmath 1993). The Khroskyabs verbal template shows several discrepancies with regards to Bybee (1985)'s relevance hierarchy: person < mood < tense < aspect < voice < verb stem. Except for the fact that voice markers in Khroskyabs are closer to the verb stem, the mood markers and the inverse marker (a kind of person marker, see Section 3.2.1) are both closer to the verb stem than the aspect/tense markers (orientational prefixes). It seems that the ordering of inflectional prefixes is not semantically motivated.

Although a verb stem in Siyuewu Khroskyabs allows for multiple prefixes, it is rare to find an example in which all the prefixal slots are filled. In natural narratives, the most elaborate verb has four prefixes (Example 2 with past, inverse, negative and autobenefactive), and some are non-prefixed stems (Example 2 in which the verb $v$ dê 'to see' does not require a prefix in the past tense).

4 The interrogative $\hat{\partial}$ - is also attested word-initially in one example, but it is very rare. See Section 3.2.2. 
(1)
a. tsoné
na-ma-n-ví
homework PST.INV-NEG-AUTOBEN-do 2
'He did not do his homework.'
b. $\jmath \hat{e} d=m \partial=t \partial=\jmath \partial=\gamma \partial \quad$ vdé
exist $_{1}=\mathrm{NMLZ}: \mathrm{S}=\mathrm{DEF}=\mathrm{PL}=\mathrm{ERG} \quad \mathrm{see}_{2}$
'Those who were there saw it.'

\section{Morphophonology of the Khroskyabs inflectional chain}

In this section, I will present the inflectional prefixes focusing on their morphophonological properties, with short comments on their functions.

\subsection{Autonomous markers in the first slots (R-1, R-2, IRR-2)}

This section provides a description of autonomous markers in the positions R-1, R-2 and IRR-2 in the verbal template.

\subsubsection{Orientational prefixes}

The orientational prefixes in Siyuewu Khroskyabs are listed in Table 2. These prefixes denote the direction of the action of the verb and bear tense-aspect-modalevidential (TAME) information. For concrete functions and uses, the reader is invited to consult Lai (2017: 305-321).

Table 2: Orientational prefixes in Siyuewu.

\begin{tabular}{ll}
\hline Prefix & Direction \\
\hline$o-$ & upward \\
$n æ-$ & downward \\
$k a-$ & sunny side (mountain) \\
$n a-$ & dark side (mountain) \\
$l æ-$ & upstream \\
$v a-$ & downstream \\
$r a-$ & neutral \\
$æ-$ & neutral \\
\hline
\end{tabular}


Orientational prefixes are hosts of most non-autonomous markers, with which they exhibit specific morphophonological processes, described in the following sections.

Their primary function is to indicate the direction to which the action of the verb proceeds, whenever it is applicable, typically with most motion or conveyance verbs. See Example (2).
a. ptsaci o-t $t^{h}$ d
Bkrashis PST:upwards-come 2
'Bkrashis came up.'
b. ptsaci næ-6âd
Bkrashis РST:downwards-go 2
'Bkrashis went down.'

The second function of orientational prefixes is to serve as an exponent of TAME categories, together with verb stem alternation. Two major classes of verbs can be distinguished through their prefixal behaviour, dynamic verbs and stative verbs. Dynamic verbs distinguish two tenses, non-past and past, and stative verbs distinguishes non-past, perfective and past imperfective. Non-past requires Stem 1 of the verb, and past and perfective Stem 2. Non-past verb forms usually take the orientational prefix rə-, and past imperfective stative verbs take only næ-. Verb forms without implication of orientation, whether stative or dynamic, are lexically assigned an orientational prefix in past or perfective. For instance, $d z \hat{\imath} d$ 'to eat' receives the prefix $o$ - 'upwards' in its past form, which yields $o$ - $d z i-n$ (PST-eat ${ }_{2}-2 \mathrm{SG}$ )

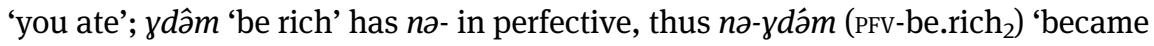
rich'.

\subsubsection{Negative markers}

Two negative markers are attested in Siyuewu Khroskyabs. The marker mo- is used in realis situations; $t \partial$ - is used in irrealis situations, essentially preceded by $\hat{a}$ - 'IRR' and imperative prefixes (which are orientational prefixes in imperative constructions). The realis negative marker mə- merges with sensory $r \hat{\partial}$ - into $m \hat{\partial} r$ - (described in Section 3.3.1). Examples are shown in (3).

a. Realis

$\eta \hat{x} n k^{h} e=r \partial \quad n u-\boldsymbol{m a}-s t^{h} \hat{e}-æ \eta$

1SG.DAT=TOP PST-NEG-feed 2 -1sG

'They did not feed me.' 
b. Imperative

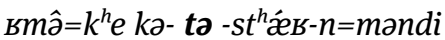

$d z_{0} \partial d \dot{a}=$ tə $l o ̂ d=d i$

fire= DAT IMP-NEG.IRR-approach ${ }_{1}-2 \mathrm{SG}=$ unless $\quad$ book=DEF $\quad$ burn $_{1}=\mathrm{ASSRT}$

'Don't go near the fire or the book will get burnt!'

c. Jussive

bjæne $\hat{a}$-to-dzid

meat JUSS.IRR-NEG.IRR-eat 1

'Don't let him eat meat.'

\subsubsection{Interrogative 6ว-}

The most common interrogative prefix in Siyuewu Khroskyabs is 62 -, forming polar questions. Its functions are discussed in Section 5.2, since it is related to the historical hypothesis of this paper. This prefix is incompatible with negative mo-, and merges with the sensory marker $r \hat{\partial}$ - into $6 \hat{\partial} r$ - (described in Section 3.3.1).

\subsection{Non-autonomous markers (R-1, R-2, IRR-1, IRR-2)}

Non-autonomous markers are dependent on other prefixes that correspond to their range in the template. There are four such markers, the inverse marker, the interrogative marker $\hat{\partial}$-, the irrealis marker $\hat{a}$ - and the HL tone conditional marker.

\subsubsection{Inverse marker}

Inverse marking is a part of person indexation in Khroskyabs, occurring on the verb mainly when the agentive argument ranks lower than the patientive argument in the empathy hierarchy $(1>2>3)$ or both arguments are third persons in transitive constructions. See the distribution of inverse marking in Table 3. For a complete description of argument indexation in Khroskyabs, see Lai (2015), Lai (2017: 415434) and Lai (forthcoming).

Table 3: Distribution of inverse marking in Siyuewu Khroskyabs.

\begin{tabular}{lllll}
\hline & & \multicolumn{3}{c}{$\mathbf{P}$} \\
\cline { 3 - 5 } & & $\mathbf{1}$ & $\mathbf{2}$ & $\mathbf{3}$ \\
\hline \multirow{3}{*}{$\mathrm{A}$} & 1 & & & \\
& 2 & INV & & \\
& 3 & INV & INV & INV \\
\hline
\end{tabular}


The inverse marker does not have a segment-level underlying form, but rather is featural in nature. It adds a (more saliently) rounded or posterior feature to its host and surfaces along with orientational prefixes and the negative prefix. With inverse, the original vowel - $\partial$ of the host becomes $-u$, and the original vowels $-o$ and -æ of the host become $-a$, see (3.2.1).

$$
\begin{aligned}
& \text { a. }-\partial+\mathrm{INV} \rightarrow-u \\
& \text { b. }--,-æ+\mathrm{INV} \rightarrow-a
\end{aligned}
$$

The second column in Table 4 illustrates the relevant plain and inverse marked prefixes (the prefix $æ$ - indicating an unknown orientation lacks inverse, interrogative and irrealis forms, and $r \partial$ - is used instead).

Table 4: Morphological processes of orientational prefixes.

\begin{tabular}{lllll}
\hline Base & Inverse & Interrogative & Irrealis & Gloss \\
\hline$o-$ & $a-$ & $\hat{o}-$ & $\hat{a}-$ & orientational prefixes \\
$n æ-$ & $n a-$ & $n \hat{æ}-$ & $n \hat{a}-$ & \\
$k \partial-$ & $k u-$ & $k \hat{a}-$ & $k \hat{a}-$ & \\
$n \partial-$ & $n u-$ & $n \hat{-}-$ & $n \hat{a}-$ & \\
$l æ-$ & $l a-$ & $l \hat{a}-$ & $l \hat{a}-$ & \\
$r \partial-$ & $r u-$ & $r \hat{-}-$ & $r a ̂-$ & \\
$m ə-$ & $m u-$ & & & negative \\
\hline
\end{tabular}

In cases where an orientational prefix and a negative prefix are combined, the orientational prefix takes inverse marking. This rule is illustrated in Example (5) with the verb yó 'to be able'. In (5a), without an orientational prefix, the inverse marker surfaces on the negative prefix, resulting in mu-yó (NEG.INv-be.able ${ }_{1}$ ), whereas in (5b), the orientational prefix $o$ - is present alongside the negative prefix $m ə-$, the inverse marker has to surface on the former, hence $a-m ə-\gamma \hat{o}$, (PFV.INV-NEGbe.able ${ }_{2}$ ).
a. $z \hat{\mathfrak{x} n d z i=j z=r a ~ r o ́ z}$
mu-yó
$n r d z \hat{o} l o=r j i \quad n u-t c^{h} \hat{\imath} d$
$\mathrm{PN}=\mathrm{GEN}=\mathrm{TOP}$ rise $_{1}$
NEG.INv-be.able 1
$\operatorname{crawl}_{1}=$ NMLZ PST.INV-induce 2
rə-クó
NPST-be 1
'Zændzi could not stand up, he was made to crawl.'

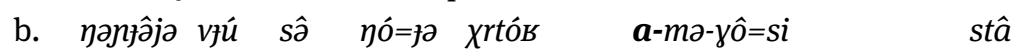 CONJ man who be ${ }_{1}=$ PL recognise ${ }_{1}$ PFV.INV-NEG-be. able $_{2}=$ IFR PART 'He lost the ability to recognise people.' 
The examples in (6) illustrate the use of the inverse prefix in the inverse configurations, $3 \rightarrow 1,2 \rightarrow 1$ and $3 \rightarrow 2$.
a. $3 \rightarrow 1$
$c \hat{\partial}=\gamma \partial \quad \eta \hat{æ} \quad \boldsymbol{k} \boldsymbol{u}-r d \tilde{u}-\eta$
$3 \mathrm{SG}=\mathrm{ERG} \quad 1 \mathrm{SG} \quad$ PST.INV-meet ${ }_{2}$-1SG
'She met me.'
b. $2 \rightarrow 1$
$n \hat{u}=\gamma \partial \quad \eta \hat{æ}, \quad \boldsymbol{k} \boldsymbol{u}-r d u ́-\eta$
2sG=ERG 1sG PST.INV-meet 2 -1sG
'You met me.'
c. $3 \rightarrow 2$

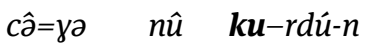
$3 \mathrm{SG}=\mathrm{ERG} \quad 2 \mathrm{SG} \quad$ PST.INV-meet ${ }_{2}$-2SG
'She met you.'

\subsubsection{Interrogative â-}

The interrogative marker $\hat{\partial}$ - is in most cases dependent on orientational prefixes, to which it assigns its falling tone, as shown in the third column in Table 4. Since the interrogative marker is tonal and forms a single phonological word with the verb stem, the verb stem loses its original tone once the interrogative marker is added. Therefore, we expect $n \hat{\partial}-t^{h} e-n$ (PST.Q-drink-2SG) instead of * $n \hat{\partial}-t^{h} \hat{e}-n$ (PST.Q-drink-2SG).

This prefix is synchronically rather unproductive: in our database, there is only one instance of independent use judged extremely uncommon by the language consultants, see (7), uttered a by a character of a story, who put a leper in a bucket and hung it under a bridge, telling him that he will be cured if he asks this character to chop off the bucket after three days staying in it.

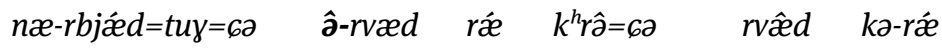

$$
\begin{aligned}
& \mathrm{PST}_{-} \text {arrive }_{2}=\mathrm{LOC}=\mathrm{CONJ} \quad \mathrm{Q}-\mathrm{chop}_{1} \text { say begin }=\mathrm{CONJ} \quad \text { chop }_{1} \quad \mathrm{INF}^{-\mathrm{Say}_{1}} \\
& \text { 'Upon arriving, I will say "should I chop”, then you say "chop”.' }
\end{aligned}
$$

\subsubsection{Irrealis $\hat{a}$ -}

The irrealis $\hat{a}$ - is mainly used in conditional protases as well as jussive constructions. Like the interrogative prefix $\hat{\partial}-$, it forms a single phonological word with the verb stem and surfaces only when there is an orientational prefix, by replacing the original vowel (see the fourth column in Table 4). 
Examples of the irrealis prefix $\hat{a}$ - are shown in (8a) for jussive and (8b) for conditional.
a. Jussive

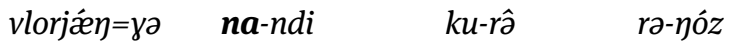
Bloring= ERG $\quad$ NPST.IRR-keep $1 \quad$ PST.INV-Say $2 \quad$ NPST-be $_{1}$
Let Bloring keep it.
b. Conditional
râa-ta-vde-n $n \hat{x} n k^{h} e \quad k \partial-r æ ́-n$
NPST.IRR-See ${ }_{1}-2 \mathrm{SG} \quad$ 1sG.DAT IMP-Say 2 -2sG
'If you don't see her, tell me.'

\subsubsection{HL tone conditional}

The HL tone conditional assigns a high falling tone to the negative irrealis prefix, the only one with which it is compatible. Its underlying segmental form is undetectable, given that it is now obsolete except in the construction in (9a). The example in (9b) shows an equivalent construction with $\hat{a}$ - 'IRR', which is comparable with the use of the HL tone conditional in (9a).

(9)
a. dzoda
næ-tว-n-vi-n
ma-câ
homework
NPST-NEG.IRR.COND-AUTOBEN-do ${ }_{1}$-2sG
NEG-be.suitable 1
'You have to do your homework (It is not right, if you don't do your homework).'

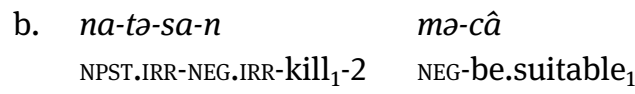
'He has to kill you (If he does not kill you, it is not good)!'

\subsection{Prefixes undergoing fusion (R-3 and IRR-3)}

Three prefixes are attested as undergoing fusion processes in specific environments, the sensory prefix rô-, the attenuative imperative prefix $m o$ - and the conditional marker $z \hat{\partial}-$.

\subsubsection{Sensory râ-}

The sensory prefix $r \hat{\partial}$ - merges with the negative prefix mə- and the interrogative prefix $6 ә-$. When it is combined with negative mə- or interrogative ${ }_{6 ə-}$, sensory $r \hat{\partial}$ - 
merges with this other prefix by leaving its tone and its initial consonant as the coda of the merger, see (10).
a. ma-râ- $\rightarrow$ mâr-
b. $6 \partial-r \hat{\partial}-\rightarrow$ câr-

In (11a), sensory rô- appears in its full form; In (11b) and (11c), $r \hat{\partial}$ - merges with the corresponding preceding prefixes.

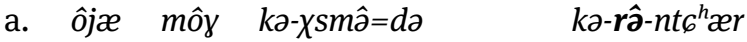
yes eye PST-close.eye ${ }_{2}=$ even PFV-SEN-appear $_{2}$
'Yes, she was there even though I closed my eyes.'
b. nêrtsa $v d \hat{\partial}=t \partial 60$ næ-mâr-va
twenty four=TOP PST-NEG.SEN-gO
'It hasn't been 24 years.'
c. mâ næ- $\mathbf{\partial} \mathbf{r}$-to
rain NPST-Q.SEN-Come 1
'Do you see it is raining?'

The sensory prefix $r \hat{\partial}$ - is employed when the speaker has direct evidence, or inference based on direct evidence, for the statement. In (12a), the speaker talks about her first-hand experience, and in (12b), the speaker makes a reasonable inference about her capability, basing the assumption on what she sees.

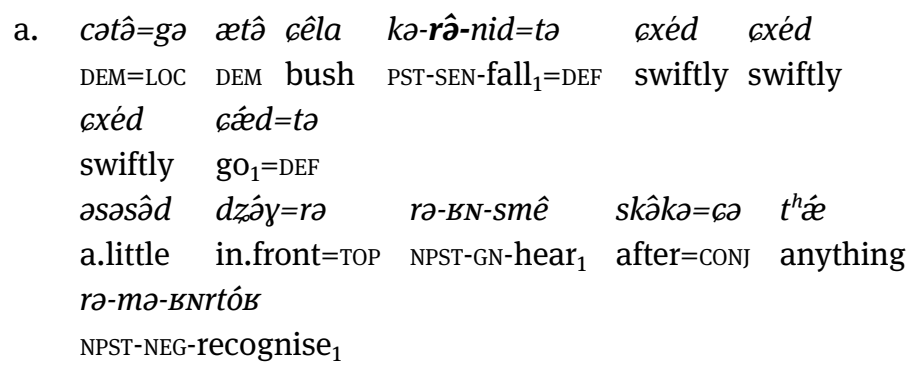

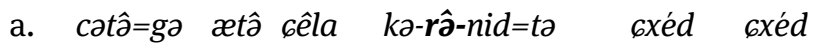
DEM=LOC DEM bush PST-SEN-fall $1_{1}=$ DEF swiftly swiftly

cxéd $6 \dot{x} d=$ to

swiftly $\mathrm{go}_{1}=\mathrm{DEF}$

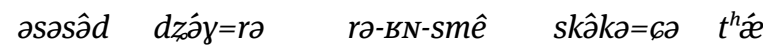

a.little in.front=TOP NPST-GN-hear ${ }_{1}$ after=CONJ anything

\section{rə-тә-вNrtós}

NPST-NEG-recognise

'The tractor suddenly fell down, at first, I heard something, but after that I was totally unconscious.'

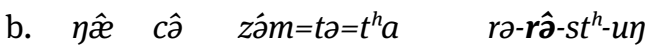
1SG DEM bridge $=$ DEF $=$ LOC NPST-SEN-be. capable 1 -1SG
'I am capable of crossing this bridge.'

\subsubsection{Attenuative imperative $\mathbf{m o}$ -}

Imperative constructions with 'mo- 'IмP.ATT' are a milder and euphemistic rendering of the normal imperative meaning. See (14b) and (14c) for examples in natural narratives. 
The attenuative imperative mo- assigns a falling tone to the imperative prefix (which is an orientational prefix selected by the verb) or the irrealis negative that precedes it. In (13), the reassignment of the falling tone is illustrated, and in (14), concrete examples are selected: an imperative example without ' mo- is shown in (14a), (14b) and (14c), the imperative prefix və- and the irrealis negative prefix təare followed by the attenuative imperative $\mathrm{mo}^{-}$, thus receiving a falling tone.

(13) a. With an orientational prefix

və-^mo- $\rightarrow$ vâmo-

b. With the irrealis negative prefix

tə-̂mo- $\rightarrow$ tâmo-

(14) a. Normal imperative

æ̂сәvæ $z \hat{x} n d z i=k^{h} e \quad l æ-v \hat{-}-n$

CONJ PN=DAT IMP-Come 3 -2SG

'Then he said to Zændzi, “come!”'

b. Attenuative imperative

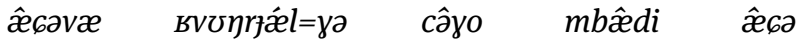

CONJ Dbangrgyal INTERJ quickly CONJ

vâmo-vâ- $n=d i=r æ=6 \partial$

IMP.IMP.ATT-Come 3 -2SG=ASSRT=Say=CONJ

'Then Dbangrgyal said, "hey there! Please come quickly!"

c. Negative attenuative imperative

$m k^{h}$ ád вbôy nə-tâmo- $t^{h} e-n$

smoke much IMP-NEG.IRR.IMP.ATT-drink $\mathrm{k}_{1}-2 \mathrm{SG}$

'Please don't smoke too much!'

\subsubsection{Conditional zâ-}

Although zâे- serves as conditional marker, it is located in a slot mainly containing realis prefixes, which is due to its late introduction in the inflectional chain (see Section 4.4). Its tone is automatically assigned to the normal negative prefix ma- if this is present, as shown in (15), and in (16a) for a sentential example. If there is no negative prefix, it retains its tone on its original syllable, as in (16b). The fusion is less complete than the other prefixes undergoing fusion, separating the tonal and the segmental parts, as in (15).

$$
m \partial-z \hat{\partial}-\rightarrow m \hat{\partial}-z \partial-
$$



a. $k^{h}$ avâ $\quad$ ææ- $\boldsymbol{m a ̂}-\boldsymbol{z} \boldsymbol{\partial}-t^{h} O d=d z \partial$
$p^{h} a \dot{d}=t^{h} a$
$o-v-\hat{o ̂} \eta$
snow PST-NEG-COND-COme ${ }_{2}=$ COND
mountain=LOC NPST- $\mathrm{gO}_{1}-1 \mathrm{sG}$
'Should it not snow, I would go into the mountain.'

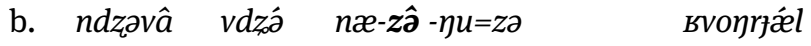
walk $_{1}$ mate PST.INPFV-COND-be ${ }_{2}=$ COND Dbangrgyal

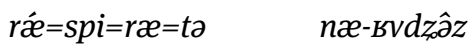
say=NMLZ:P=one=DEF PST.IPFV-join 2
'As for the one who accompanied me, it was someone called
Dbangrgyal.'

\subsection{Wordhood of the Siyuewu verb}

The morphophonology of the inflectional chain having been explained, it is necessary to mention the wordhood of the Siyuewu verb to show that the inflectional chain forms a single word with the verb stem.

As Bickel and Zúñiga (2017: 184-185) put it, "words” in polysynthetic languages ${ }^{5}$ are "often not unified entities defined by a single domain on which all criteria would converge." The case of Siyuewu Khroskyabs is not an exception. However, in the Khroskyabs verbal complex, morphosyntactic and phonological boundaries converge relatively well, and seven distinct criteria (based on Dixon and Aikhenvald 2002: 18-25; Haspelmath 2011; Hyman 2006) point to a single prosodic domain, which I henceforth refer to as "verbal word".

The Siyuewu verbal word conforms to most of the criteria proposed by Dixon and Aikhenvald (2002: 18-25). First, according to the criterion of cohesiveness stating that grammatical words always occur together, the Siyuewu verbal word is never attested separated. Second, as is shown in the morphonological description, the morphemes within a verbal word in Siyuewu Khroskyabs occur in a fixed order, which is the second criterion of Dixon and Aikhenvald (2002). ${ }^{6}$ Third, Siyuewu verbal words have a conventionalised coherence and meaning: when talking about a verb, native Khroskyabs speakers usually have two options: one is to offer the citation form, which is usually the bare stem, the other is to conjugate the verb into a finite form. They are seldom aware of bound morphemes. When directly asked about an affix, they cite a whole verb form containing the affix in question. For instance, when asked about the orientational prefix næ- 'downwards', native

5 See Haspelmath (2018) for a contestation of polysynthesis.

6 One should note that this criterion was challenged by Bickel et al. (2007), who discovered free morpheme permutation within a grammatical word in Chintang and other Kiranti languages, which are genetically related to Khroskyabs. 
speakers offer a verb form such as næ-vô, (NPST:downwards-go1) 'S/he goes downwards/they go downwards'. Haspelmath's (2011) "nonextractability" is similar to this criterion. Fourth, I have never found an example with a pause inside a verbal word, nor could I elicit such an example. The near-impossibility of internal pausing is mentioned in Dixon and Aikhenvald (2002) and Haspelmath (2011) (as "potential pauses"). Fifth, the verbal word in Siyuewu Khroskyabs is often attested as a complete utterance ("free occurrence" in Haspelmath 2011), as is shown in (17).

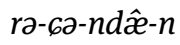

$$
\begin{aligned}
& \text { NPST-Q-like }{ }_{1} \text {-2sG } \\
& \text { 'Do you like it?' }
\end{aligned}
$$

Sixth, the uninterruptibility criterion (Haspelmath 2011), stating that a grammatical word cannot be interrupted by another word, is suitable for the Siyuewu case synchronically. Lastly, the criterion of culminativity (Hyman 2006: 231) states that every lexical word has at most one syllable marked for the highest degree of metrical prominence. In Siyuewu, only one of its syllables bears a tone, and the tonal realisations of the other syllables are derived from this tone. If an affix is intrinsically tonal, its employment results in the loss of the tone of the verb stem, as is shown in (3.4), where the tone of the stem $t^{h} e$ 'drink' drops when the jussive marker is added.

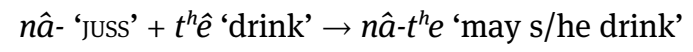

In a nutshell, the Siyuewu verbal complex should be considered a grammatical word with a long inflectional chain and a verb stem. However, I will show that the inflectional chain was not a part of the verb stem at an earlier stage, and discuss the historical development of the inflectional prefixes.

\section{The historical layers of the Siyuewu inflectional chain}

In this section, I will identify different historical layers in the Siyuewu inflectional chain. Three factors will be taken into account according to the theoretical frameworks cited earlier.

1. Degree of fusion: older prefixes are more likely to fuse with their hosts.

2. Productivity and usage constraints: older prefixes tend to be less productive.

3. Cross-Gyalrongic comparison: older prefixes are more likely to have cognates in related languages. 


\subsection{Degree of fusion and compatibility}

The morphophonological description in Section 3 shows that the inflectional prefixes undergo different degrees of fusion. Some are cases of full merger, in which the original form of the separate prefix can no longer be recovered; some cases are incomplete mergers, in which segmental traces of the prefix under question can be found; other prefixes undergo little or no fusion at all. Table 5 is a summary of the different degrees of fusion attested in the Siyuewu inflectional chain. It clearly shows the gradual decrease in degree of fusion from the outermost slot to the innermost one.

Table 5: Degrees of fusion in the Siyuewu inflectional chain.

\begin{tabular}{|c|c|c|c|}
\hline Positions & Slots & Degrees of fusion & Examples \\
\hline \multirow[t]{3}{*}{$\begin{array}{l}\text { Outermost } \\
\text { slots }\end{array}$} & $\mathrm{R}-1 \sim \mathrm{R}-2$ & Full merger & $\begin{array}{l}\text { Inverse and } \hat{\partial}-\text { ' } Q \text { ' with orientational } \\
\text { prefixes }\end{array}$ \\
\hline & & $\begin{array}{l}\text { Mutual } \\
\text { incompatibility }\end{array}$ & 62 'Q' and $m \partial-$ 'NEG' \\
\hline & IRR-1 IRR-2 & Full merger & HL tone conditional with ta- 'NEG.IRR' \\
\hline \multirow[t]{2}{*}{ Middle slots } & $\mathrm{R}-2 \sim \mathrm{R}-3$ & Incomplete merger & $\begin{array}{l}\text { râ 'SEN' with 6ə- 'Q' and ma- 'NEG' (6âr-, } \\
\text { mâr-) }\end{array}$ \\
\hline & IRR-2 $\sim$ IRR-3 & & tâ 'NEG.IRR' with ^mo- (tâmo) \\
\hline Innermost slot & $\begin{array}{l}\mathrm{R}-2 \sim \mathrm{R}-4 \\
\mathrm{R} 4\end{array}$ & $\begin{array}{l}\text { Displacement of tone } \\
\text { No fusion }\end{array}$ & $\begin{array}{l}\text { ma- 'NEG' with zâ- 'COND' (mâ-zə) } \\
\text { də- 'even' }\end{array}$ \\
\hline
\end{tabular}

In the outer slots, the inverse marker, the interrogative marker $\hat{\partial}$ - and the HL tone conditional, whose original forms are either totally unknown or seldom attested, fully merge with their respective hosts. In the middle slots, the sensory marker $r \hat{\partial}$ - partially merges with $m \partial$ - 'NEG' and $\iota^{2}$ - 'Q' to $m \hat{\partial} r$ - and $\iota \hat{\partial} r$ - respectively; 'mo- 'IMP.ATT' merges with orientational prefixes into Cô/ $\hat{x} / \hat{o} m o-$ and with ta'NEG.IRR' in to tâmo-. The incompatibility of mə- 'NEG' and $6 \partial$ - 'Q' needs to be interpreted specifically, as it is surprising both from a typological perspective and within Gyalrongic. In Japhug, combinations of 'ú- 'Q' and mu- 'NEG' result in a new prefix expressing the Possible modality, umr- 'Poss', and this prefix is attested in various narratives (Jacques ms); and in Bragbar Situ, instances with mə-ma(Q-NEG-) are not hard to find, as shown in (19). 
a. Japhug

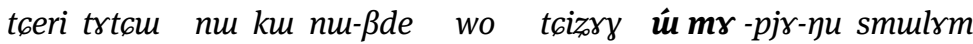
LNK boy DEF ERG IMP-throw INTERJ 1DU.GEN POSB-IPFV-be prayer nu to-ti

PART PFV-Say

'The boy said, "forget about it, let's hope that (these things) are ours.", (Jacques 2010b)

b. Bragbar Situ

\begin{tabular}{|c|c|c|c|}
\hline & $u-\eta k^{h} \bar{u}$ & tбena s & dewatcên tce \\
\hline $\begin{array}{l}\text { FV-not.exist }{ }_{2} \text {-PST } \\
e-k a-s c \hat{p}\end{array}$ & $\begin{array}{l}\text { 3SG-POSS-back } \\
\boldsymbol{m a -} \boldsymbol{m a}-c^{h} \hat{a}\end{array}$ & $\begin{array}{l}\text { conj Bouddha } \\
k a \text {-sasō }\end{array}$ & LOC \\
\hline
\end{tabular}
TRANSLOC-INF-be.born Q-NEG-be.capable GN:S/A.voL-think

'After my father's death, what I thought was, "could he not be reborn in Sukhāvatī?”, (P.C. Zhang Shuya, 29 March 2018)

The incompatibility between interrogative and negative is atypical enough to reject a semantic explanation. Rather, it seems that there was a maximality constraint, causing syllable reduction or deletion processes (Hildebrandt 2015: 231), that prohibited the sequence of ma-6ว- (NEG-Q-). This sequence cannot be repaired by fusion like $r \hat{\partial}$ - 'SEN' in the same position, since * $m \partial \epsilon$ is phonotactically impossible in Khroskyabs. As a consequence, a restriction on co-occurrence was the only option. This incompatibility should be considered equivalent to a fusion. The constraint is illustrated in (5). As I will show later, the maximality constraint was only at work in an earlier stage in the evolution of the inflectional chain, and affected only the slots before R-4.

Maximality constraint

a. I ORIEN-ma/ढə-rô- (Violation of maximality constraint)

II ORIEN-mâr/6âr- (Fusion)

b. I ORIEN-mว-6ว-(Violation of maximality constraint)

II ORIEN-mə- or ORIEN-6ə- (Mutual exclusion)

Maximality constraints are found elsewhere, for instance in sign languages where the maximal size of a sign usually consists of two syllables (Hohenberger 2007: 351). In spoken languages, for example, Yidiny (Glottolog: yidi1250) trisyllabic verb stems undergo final syllable deletion when followed by two syllables. See the examples in (21). In (21a), the maximality constraint is not violated as the stem is disyllabic, therefore the two suffixes are pronounced; in (21b), the final suffix is deleted with a compensatory lengthening of the penultimate syllable, as the constraint is violated. 


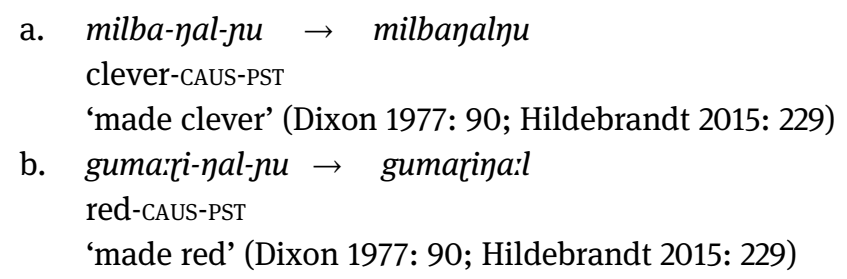

While the outer slots are within the scope of the maximality constraints, the inner slots are not. As will be shown further, the prefixes in the inner slots are exempt from the maximality constraint due to their late integration. In the innermost slot, only the conditional $z \hat{\partial}$ - presents a slight tendency of fusion. Its tone is displaced to the preceding $m \partial$ - 'NEG' to create the sequence $m \hat{\partial}-z \partial-$-, while $d \partial$ - 'even' does not exhibit any morphophonological process at all. Note that $-z$ and $-d$ are legal codas in Siyuewu Khroskyabs, yet in spite of this, the two prefixes in the innermost slot do not merge with preceding prefixes.

\subsection{Productivity and usage constraints}

In this section, I discuss the productivity or usage constraints of certain relevant prefixes in the inflectional chain. I will mainly focus on the prefix pairs presenting functional overlaps in the inflectional chain, in order to show their different degrees of productivity and the correlation between productivity and prefix positions.

\subsubsection{Orientational prefixes}

Orientational prefixes in Siyuewu Khroskyabs present some strict usage constraints. Although they can be attached to most verbs, a good portion of their uses are fossilised.

Firstly, the spatial function of the orientational prefixes does not always match how they are labelled in Table 2. To give some examples, two places, Bragbar (白 湾 Báiwān) and $\eta k^{h}$ orján (可尔因 Kě ěryīn), are very close to each other (4 km of driving distance), presumably without a significant difference from either of these two places to Dzamthang (壤塘 Răngtáng), which is $157 \mathrm{~km}$ away up. However, two different orientational prefixes are employed. From $\eta k^{h} o r j a ́ n$, the prefix $o$ - 'upwards' is used, while from Bragbar, kə- 'sunny side of the mountain' must be chosen. Another case concerns the prefixes used between Wobzi (俄热 Ére) and Thugschen (观音桥 Guānyinnqiáo). From Wobzi to Thugschen, və- 'downstream' is used. One might expect the return trip will favour the prefix of the opposite direction, læ- 'upstream', but actually, $k a$ - 'sunny side of the mountain' is used. A 
recent study, Lai (2018), shows that the use of Siyuewu orientational prefixes matches $73 \%$ of the geographical reality.

Secondly, the TAME functions of orientational prefixes are highly lexicalised. Like Tshobdun Gyalrong (Sun 2003: 496) and Wobzi Khroskyabs (Lai 2017: 441) (and probably all Gyalrongic languages), orientational prefixes are lexically assigned to the Stem 2 of verbs in perfective or past tense. Fossilisation and conventionalisation are a sign of the antiquity of the orientational prefixes in Siyuewu Khroskyabs, which may well have undergone several waves of development and innovation.

\subsubsection{Negative prefixes}

The two negative prefixes, mə- 'NEG' and to- 'NEG.IRR' are in complementary distribution based on the modality, as shown in Section 3.1.2. The division of labour in terms of modality is probably not a recent phenomenon. This phenomenon is actually well-known in typology, called "asymmetric negation" by Miestamo (2005). Typological studies show a general tendency for irrealis constructions, such as imperatives and prohibitives, to have a different negator from realis constructions (Miestamo and van der Auwera 2007; van der Auwera and Lejeune 2013). An example is Classical Latin, with the negative markers nōn and ne, which are employed in different situations depending for the most part on the mood. Generally, nōn is used in declarative and interrogative sentences, and $n \bar{e}$ in imperative sentences. While $n \bar{e}$ is derived from Proto-Indo-European * $n e$ 'NEG', nōn is a contraction of Old Latin noenum 'NEG', which can be traced back to ProtoIndo-European *ne-oinom 'no one' (de Vaan 2008: 403). Similarly, the distribution of mo- 'NEG' and to- 'NEG.IRR' in Siyuewu should have been developed over an extended length of time.

\subsection{3 $\hat{\partial}-$ ' $Q$ ' and 6ว- ' $Q$ '}

The interrogative marker $\hat{\partial}$ - is much less productive than its competitor $6 \partial^{-}$, it is only rarely used in modern Khroskyabs, as is explained in Section 3.2.2. By contrast, the prefix 62 - is by far the more common interrogative marker in Siyuewu Khroskyabs.

\subsubsection{Conditional markers and the irrealis category}

There are three markers that can be used in conditional protases, $\hat{a}$ - 'IRR', the HL tone conditional, and $z \hat{\partial}$ - 'ConD'. They exhibit different degrees of productivity. While $\hat{a}$ - 'IRR' can be used freely with intransitive verbs as in (22a), it can only occur with a transitive verb in inverse scenarios, as in (22b) with the verb $f_{6} \hat{x} d$ ' to speak'. 
a. Intransitive

\begin{tabular}{|c|c|c|c|}
\hline ætâ & $\boldsymbol{n} \hat{\boldsymbol{a}}-\operatorname{ma\gamma }=z \partial$ & $\hat{j} \hat{\imath}=t \partial$ & $\boldsymbol{n} \hat{\boldsymbol{a}}-\boldsymbol{N} q^{h} l æ=6 \partial$ \\
\hline DEM & NPST.IRR-be. not $_{1}=$ COND & soul=DEF & NPST.IRR-get.out ${ }_{1}=\mathrm{CONJ}$ \\
\hline$\hat{j} \hat{\imath}=t \partial$ & $d j \hat{u}=\gamma \partial \ldots$ & пว-тว-ь & T-tô \\
\hline soul=DEF & ghost=ERG & NPST-NEG & N-become ${ }_{1}$ \\
\hline
\end{tabular}

'If you don't do that, if the soul gets out, the ghost will ... your life will become shorter.'

b. Transitive (inverse scenario)

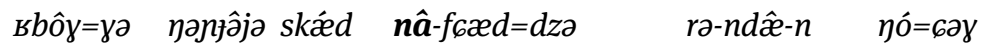
many=ERG CONJ speech NPST.IRR-Speak ${ }_{1}=$ COND NPST-like ${ }_{1}-2 \mathrm{SG}$ be $_{1}=\mathrm{Q}$ 'So if many people talk a lot, you like this, right?'

The HL tone conditional is only compatible with ta- 'NEG.IRR', as already shown in (9a). The only conditional marker that is fully productive is $z \hat{\partial}-$, whose use is always accompanied by the quasi-homophonous enclitic =zə, see Example (16).

\subsubsection{Productive prefixes}

The sensory prefix rầ- and də- 'even' are fully productive, see Sections 3.3.1 and 5.1.

\subsubsection{Summary}

The general tendency is that the prefixes in the outer slots are less productive, and those in the inner slots are relatively more productive. This is particularly clear within competing prefixes, 6ə- 'Q' and $z \hat{\partial}$ - 'COND', both situated closer to the verb stem, which are more productive than their respective competitors whose positions are more peripheral. Although the prefixes without competitors must preserve some productivity, they tend to be less productive and more lexicalised in the outer slots than in the inner slots. The prefixes analysed in this section are summarised in Table 6, illustrating the correlation between the positions of the prefixes and their respective productivity.

Table 6: Correlation between prefix position and productivity.

\begin{tabular}{lllll}
\hline & Outer & & & \\
\hline Prefix & ORIEN & ma-, ta- (NEG) & râ- 'SEN' & zâ- 'COND' \\
Productivity & Moderate & Moderate & High & High \\
Prefix & $\hat{\partial}-$ 'Q' & $6 \partial-$ 'Q' & & də- 'even' \\
Productivity & Low & High & & High \\
Prefix & $\hat{a}-$ 'IRR' & COND (HL tone) & & \\
Productivity & Moderate & Low & & \\
\hline
\end{tabular}




\subsection{Cross-Gyalrongic comparison}

Some inflectional prefixes in Siyuewu Khroskyabs have cognates in other Gyalrongic languages, and some do not. I will show that the prefixes having Gyalrongic cognates are situated in the outer slots.

\subsubsection{Orientational prefixes}

The category of orientational prefixes is found in all Gyalrongic languages, and there are quite a few orientational prefixes shared by most of them. In Table 7, cognates of orientational prefixes between Siyuewu Khroskyabs, Japhug and Horpa (Khang.gsar Horpa unless indicated otherwise) are illustrated. Out of all eight orientational prefixes in Siyuewu Khroskyabs, seven have cognates in other Gyalrongic languages.

Table 7: Cognates within orientational prefixes.

\begin{tabular}{llllll}
\hline Khroskyabs & Gloss & Japhug & Gloss & Horpa & Gloss \\
\hline$o-$ & upwards & & & $\partial-$ (Gyurong) & upwards \\
$n æ-$ & downwards & & & $n \partial-$ & downwards \\
$k \partial-$ & sunny side (mountain) & $k \gamma-$ & east & $k \partial-$ & northwest \\
$n ə-$ & dark side (mountain) & $n u-$ & west & & \\
$l æ-$ & upstream & $l \gamma-$ & upstream & & \\
və- & downstream & pu- & downwards & yə- & southeast \\
$r ə-$ & neutral & & & tə- & neutral \\
\hline
\end{tabular}

\subsubsection{Interrogative $\hat{a}$ -}

Between the two interrogative prefixes in Khroskyabs, $\hat{\partial}$ - has related forms in other Gyalrongic languages. It is related to Khang.gsar Horpa í-, not to mention many Gyalrong languages such as Japhug $u$ u- This interrogative prefix could be a borrowing from Tibetan (Glottolog: tibe1272) in Proto-Gyalrongic (Gong 2018: 283), but it certainly existed before the separation of Khroskyabs from Gyalrong.

\subsubsection{Irrealis $\hat{a}$ -}

The irrealis prefix $\hat{a}$ - is related to $a$ - 'IRR' in Japhug, $\boldsymbol{e}$ - 'IRR' in Tshobdun (Sun 2007) and $o$ - 'IRR' in Bragbar Situ, which are all Gyalrong languages. The irrealis prefix in Khang.gsar Horpa is homophonous with its interrogative prefix $i^{-}$, occupying the same position, after the orientational prefix. Geshizha Horpa presents a general 
irrealis in $\partial^{-}$, which is comparable to Khang.gsar Horpa $i^{-}$, while its optative marker $a$ - is related to Khroskyabs $\hat{a}$ - (Honkasalo 2018). Given that cognates are found in both sub-branches, it is safe to say that $\hat{a}-$ can be reconstructed into ProtoGyalrongic.

\subsubsection{Negative prefixes}

In Gyalrong languages, negative prefixes are formed with the bilabial nasal consonant $m$ - (Japhug $\mathrm{mu}-/ \mathrm{mr}^{-}$, Bragbar Situ mə-), cognate to mə- in Siyuewu Khroskyabs. Horpa varieties are more comparable to the Khroskyabs case. Khang.gsar Horpa exhibits $m i-/ m a-$ 'NEG' related to Khroskyabs mə-, and di- 'NEG.IRR' to Khroskyabs to-.

Negative markers beginning with a bilabial nasal are common in TransHimalayan languages (Post 2015: 432), while a stop-initial negative marker is less frequently reported. Although the negative irrealis prefix ta- is only comparable to Horpa di- inside Gyalrongic, it has correspondences in other Trans-Himalayan families, for example, the Bodo (Glottolog: bodo1279) prohibitive ta- (DeLancey 2015: 53). Gyalrong languages have lost this old prefix, while Khroskyabs and Horpa preserved it.

\subsubsection{Inverse marker}

Inverse marking is found in all Gyalrongic languages (DeLancey 1981; Gong 2014; Jacques 2010a; Jacques et al. 2014; Sun and Danluo 2002; Gates and 'ja' dPal ms; Zhang 2019), and their markers are obviously cognates. Inverse prefixes either have rounded or labial features, such as wy- in Japhug, wə- in $\mathrm{Zbu}, o$ - in Bragbar, and $v$ - in Khang.gsar Horpa.

\subsubsection{Attenuative imperative 'mo-}

The attenuative imperative $\hat{m}$ o- is not found in Gyalrong languages, but may have cognates in other West Gyalrongic languages. Although the link is not crystal clear, this marker could be related to the hypothetical particle mo in Mazur Horpa (Gates forthcoming), or even to the irrealis sentence final particle 路 $\mathrm{mo}^{7}$ in Tangut (Glottolog: tang1334) (Lai et al. forthcoming).

7 The four-digit number under the Tangut character is its code in Li Fanwen's dictionary (Li 1997). 


\subsection{Identification of the historical layers}

We analysed the inflectional prefixes from three perspectives: degree of fusion, productivity and usage constraints. These three different analyses show similar and consistent tendencies, shown in Table 8. Outer prefixes show a higher degree of fusion, lower productivity and are more likely to be inherited from ProtoGyalrongic; inner prefixes show a lower degree of fusion, higher productivity and usually do not have cognates in Gyalrong or Horpa; they are probably innovations. Contrary to the typological tendency, outer prefixes are older than inner prefixes in Siyuewu.

Table 8: Correlation among degree of fusion, productivity and inheritance.

\begin{tabular}{llll}
\hline Position & Outer & $\Longleftarrow$ & Inner \\
\hline Degree of fusion & High & $\Longleftarrow$ & Low \\
Productivity & Low & $\Longleftarrow$ & High \\
Inheritance & Inherited & $\Longleftarrow$ & Innovated \\
\hline
\end{tabular}

Three major layers in the inflectional chain can be distinguished.

The outermost and oldest layer, is comprised of all the prefixes in R-1 and IRR-1, and most of those in R-2 and IRR-2. These prefixes are inherited from ProtoGyalrongic, with relatively lower productivity, some of them are even without a separate form synchronically.

The middle layer includes prefixes in R-2, R-3 and IRR-3: 6ə- 'Q', $r \hat{\partial}$ - 'SEN' and mo-. These prefixes are more recent than Layer 1, exhibiting partial fusion with the preceding prefix. It seems that until this stage, there had been a maximality constraint regarding the inflectional chain, where a maximum of two surface slots were allowed. This can explain the fusion of $r \hat{\partial}$ - and $m o$ - 'IMP.ATT' with the preceding slot, and the unusual incompatibility of 62 - ' $\mathrm{Q}$ ' and $m \partial$ - 'NEG', see Section 4.1.

The innermost and most recent layer contains the prefixes in R-4: $z \hat{\partial}-$ 'ConD' and də- 'even'. These two prefixes exhibit high degree of productivity and low degree of fusion (or no fusion at all). Furthermore, these two prefixes are both in the realis series, despite the fact that $z \hat{\partial}$ - 'COND' is semantically irrealis. This observation suggests that the irrealis slots ceased to be productive before $z \hat{\partial}$ - entered the inflectional chain, which further confirms our analysis.

Table 9 shows the historical layers of Siyuewu inflectional prefixes in the verbal template. The Khroskyabs inflectional prefixes go against the universal tendency. Although the details of the present prefix ordering may be skewed by 
other factors, our analysis shows the overall ordering faithfully reflects the historical layers.

Table 9: Historical layers of the Khroskyabs inflectional chain.

\begin{tabular}{|c|c|c|c|c|c|}
\hline & & \multicolumn{2}{|c|}{ Layer 1} & \multirow{2}{*}{$\begin{array}{l}\text { Layer } 2 \\
\text { R-3 }\end{array}$} & \multirow{2}{*}{$\begin{array}{l}\text { Layer } 3 \\
\text { R-4 }\end{array}$} \\
\hline & & R-1 & $R-2$ & & \\
\hline \multirow[t]{3}{*}{ Realis } & N-AUTO & $\begin{array}{l}\text { INV } \\
\hat{\partial}-\text { ' } Q \text { ' }\end{array}$ & & & \\
\hline & AUTO & ORIEN & $\begin{array}{l}\text { ma- 'NEG' } \\
\text { 6ə- 'Q' }\end{array}$ & râ- 'SEN' & $\begin{array}{l}z a \hat{a}-\text { 'COND' } \\
\text { də- 'even' }\end{array}$ \\
\hline & & IRR-1 & IRR-2 & IRR-3 & \\
\hline \multirow[t]{2}{*}{ Irrealis } & N-AUTO & $\hat{a}-$ 'IRR' & COND (HL tone) & & \\
\hline & AUTO & ORIEN & ta- 'NEG.IRR' & mo- 'IMP.ATT' & \\
\hline
\end{tabular}

\section{How prefixes are integrated: cases of da- 'even' and 62 - ' $Q$ '}

In this section, I focus on the evolution of two innovated prefixes in Khroskyabs, də- 'even' and 6ə- 'o', whose evolutionary pathways are relatively clear. Both of them evolved from enclitics postposed to hosts, and ended up prefixes.

In Sections 5.1 and 5.2, I provide synchronic descriptions of the two prefixes and their corresponding enclitics, before postulating hypotheses about their evolutionary pathways in Sections 5.3 and 5.4. In Section 5.5, I propose an alternative hypothesis.

\section{1 də- 'even' and =da 'also, even'}

The enclitic $=d \partial$ can serve as an inclusive focus marker, meaning 'also', as well as an additive focus marker, meaning 'even'. The prefix də- can only serve as an additive focus marker, meaning 'even'. 8

The prefix do- 'even' occupies the position closest to the verb stem. Its usage is straightforward, usually in a negative environment, emphasising a contrast between what is expected and the reality. In (23) for instance, the speaker, talking about his own experience, was supposed to sleep but could not.

8 For the terms inclusive and additive foci, see König (1991: 60-91). 


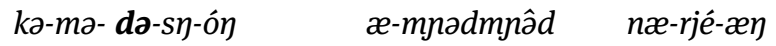

$$
\begin{aligned}
& \text { PST-NEG-even-sleep }{ }_{2} \text {-1sG DEM-appearance } \text { PST-sit }_{2} \text {-1sG } \\
& \text { 'I didn't even sleep, and was sitting like that.' }
\end{aligned}
$$

This prefix is clearly related to the homophonous adverbial enclitic =do 'also, even' which has multiple connotations and uses, unlike the prefix whose meaning is limited to 'even'.

The primary meaning of $=d \partial$ is 'also', which marks a similar or comparable event to another event that is previously mentioned. See the examples in (24). There are two comparable events in Example (24a), the first one being the offering of some tsampa, and the second one the offering of a secret. The enclitic $=d a$ has its scope over the second event, marking the similarity between the two. Similarly, in Example (24b), the character uses = do after knowing that his interlocutor has burnt another house. Notice that in this example, $=d \partial$ is added to the genitive pronoun $\eta \hat{x} n$ '1sG.GEN', instead of the entire noun phrase. The positioning of =də is relatively free inside its scope.

$$
\begin{aligned}
& \text { a. } \eta \hat{x} n k^{h} e \quad p^{h \hat{\partial} t \epsilon^{h} a=r æ} \quad n u-b-\hat{o} \eta=6 \partial \quad n u ̂ n k^{h} e \\
& \text { 1sG.DAT tsampa=one IMP-give. } \text { food }_{1}-1 \mathrm{sG}=\mathrm{CONJ} \text { 2SG.DAT }
\end{aligned}
$$

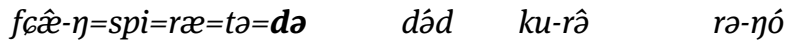

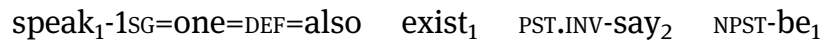

$$
\begin{aligned}
& \text { “"Give me some tsampa, and I also have something to tell you." It }
\end{aligned}
$$

The enclitic $=d \partial$ can also function as an additive focus marker, exemplified in (25a) and (25b).
a. $\hat{\gtrless} 6 \partial \quad t^{h}$
$n æ-\eta \partial ́ m=s k a=v æ$ njê sâ CONJ any IPFV.PST-be.ill ${ }_{2}=\mathrm{NMLZ}=\mathrm{CONJ}$ 2sG who $\eta o ́-n=v æ$ âsad $=$ do mə-вNrtóв-n

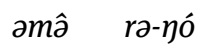 a.little=even NEG-recognise ${ }_{2}-2 \mathrm{sG} \quad$ DUB $\quad$ NPST-be $_{1}$ 'When I was ill, I wouldn't recognise who you were, not even a little.'
b. só th'́ æmpâd nə-nsc-ón $n t s^{h} \hat{\partial} s^{h} e-æ \eta=s p i=d \boldsymbol{\partial}$ more any that.way IPFV.PST-be.afraid ${ }_{2}-1 \mathrm{sG}$ think $\mathrm{k}_{1}-1 \mathrm{sG}=\mathrm{NMLS}=\mathrm{even}$ ra-mid NPST-not.exist

'I was so afraid and couldn't even think about anything more.' 
When the enclitic $=d \partial$ is used as an additive focus marker, it commonly occurs in a fixed reduplicated construction as shown in (26). The construction involves the Stem 1 of a verb marked with the enclitic $=d \partial$, emphasising the focused event, followed by the same verb inflected, reflecting the actual event. This use is illustrated in (27). This construction is related to our hypothesis to be presented in Section 5.3.

(26) $\quad[$ Verb] $]=d \partial \quad$ [inflection]-[Verb]

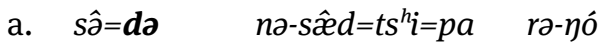
die $1=$ even $\quad$ PST-die $2=$ IFR=NMLZ $\quad$ NPST-be 1
'He even died (As for dying, he did die equally).'

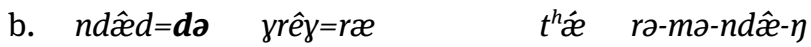
like $_{1}=$ even superfluous $=$ one any NPST-NEG-like $_{1}-1 \mathrm{sG}$
'I don't even like a bit of it (Like it? I don't even like a bit of it).'

\section{$5.262-$ ' $Q$ ' and =6วy ' $Q$ '}

The interrogative prefix 62 - occupies the slot R-2 in the inflectional chain, and belongs to the second historical layer. It is not compatible with the negative prefix ma-, which is in the same slot. Despite being one of the older prefixes, it is clearly related to the question enclitic $=6 \partial \gamma$, which also marks polar questions. In modern Khroskyabs, the prefix 62 - and the enclitic $=6 \partial y$ are mostly in complementary distribution. The enclitic is basically attested with non-prefixed stems. Examples are shown in (28), with the same verb, ๆo 'to be'.

$$
\begin{aligned}
& \text { a. mâve norscâd=jə=væ gáv=tə } æ t \hat{\partial}=\gamma \partial \\
& \text { grandmother Norskyid }=\mathrm{GEN}=\mathrm{TOP} \quad \text { foot }=\mathrm{DEF} \quad \mathrm{DEM}=\mathrm{INSTR} \\
& \text { næ-blî } \quad \eta \dot{l}=\boldsymbol{c} \boldsymbol{\partial} \\
& \text { PST-be.responsible } 2 \quad \text { be }_{1}=\mathrm{Q} \\
& \text { 'The injury of Grandma Norskyid's foot was because of that, wasn't it?' }
\end{aligned}
$$

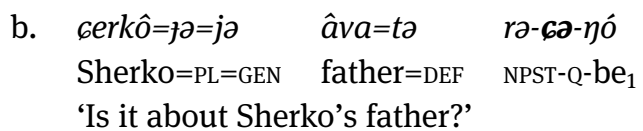

Although the enclitic $=6 \partial y$ is productively attested only with non-prefixed stems, there is still one fossilised reduplicated construction that allows its occurrence with prefixed stems, shown in (29). An example is illustrated in (30). This construction might well be related to the emergence of the prefixal counterpart, 62 (see Section 5.4). 


$$
\text { [INFLeCTION]-[Verb]=6วy [INFLECTION-NEG]-[Verb] }
$$

$n æ-\chi f s c a ́ r=6 а \gamma \quad n æ-m ə-\chi f s c a ́ r$

IPFV.PST-be. afraid $_{2}=0 \quad$ IPFV.PST-NEG-be. afraid $_{2}$

'Was he scared? Was he not scared?'

\subsection{Integration of $d \partial-$ 'even'}

In this section, I present my hypothesis on the integration of $d \partial-$ 'even'. In the first place, I propose the direction of semantic change from $=d \partial$ 'also, even' to $d \partial$ - 'even' (Section 5.3.1), and then, I propose the evolutionary pathway of the integration by simplifying an original double word construction as well as clitic reassignment (Section 5.3.2).

\subsubsection{Semantic narrowing from =da 'also, even' to da- 'even'}

Regarding the diachronic relationship between the prefix do- 'even' and the enclitic $=d \partial$ 'also, even', two pathways can be hypothesised.

1. The enclitic $=d \partial$ is derived from the prefix $d \partial-$.

2. The prefix $d \partial$ - is derived from $=d \partial$.

Opting for the first hypothesis implies a process of degrammaticalisation, as it implies the separation of the prefix $d \partial$ - from the prefix chain and the creation of a freer morpheme, the enclitic $=d$. . Degrammaticalisation was coined as a term in 1982 by (Lehmann 2015: 18-21). A pathway from an affix to clitic is termed "deinflectionalisation" by (Norde 2011), attested in English, Swedish and Kwaza (Glottolog: kwaz1243). However, such cases remain very rare, and are considered "by far the least common" type of degrammaticalisation (Norde 2011: 478). By contrast, the pathway from a clitic to an affix, which is referred to as the hypothesis of unidirectionality, is typologically more plausible (Hopper and Traugott 2003: 111). As for the case of Siyuewu Khroskyabs, I have shown that da- 'even' is a Khroskyabs-specific innovation, not attested in the rest of the Gyalrongic languages, and the semantic range exhibited by $d \partial$ - 'even' is narrower than $=d \partial$ 'also, even', which fits the principle of persistence in the process of grammaticalisation (Hopper 1991: 28) as well as the characteristics of semantic retention (Bybee et al. 1994: 15-17). Moreover, 'also' is more likely to be the source of grammaticalisation, and 'even' the target (Heine and Kuteva 2002: 43, 330): the English adverb even itself is derived from a still extant meaning of 'equal, level', which is close to 'also' 
(Partridge 2006: 1006). The second hypothesis is therefore more straightforward, with the prefix də- derived from the enclitic $=d \partial$.

As the prefix do- only preserves the meaning 'even' out of the two meanings of its corresponding enclitic, it is natural to assume that the semantic narrowing took place constructions with the meaning of 'even', and the most likely construction is the one presented in (26).

\subsubsection{Simplification of double verb construction and clitic reassignment}

The examples in (27) are double verb constructions with a bare verb marked by $=d \partial$ 'even', followed by a finite form of the same verb. This kind of construction is typical in languages with verb doubling involving the infinitive or citation form of the main verb or verb phrase placed before the original sentence, expressing verbal toplicalisation of focus (Hein 2017). The phenomenon can be found in many languages around the world, to name a few, Polish (Glottolog: poli1260) (Bondaruk 2009: 65), Ewegbe (Kwa) (Glottolog: ewee1241) (Ameka 1992: 12) and Sranan Tongo (Glottolog: sran1240) (Parkvall 2000: 89).

A reverse case is found in Mandarin Chinese (Glottolog: mand1415), with 也 yě also or 都 dōu 'all', as shown in (32). ${ }^{9}$ The same meaning can be expressed by a double verb construction, as in (32a), and by the sentence in (32b), with the first verb optionally omitted, that is, the single verb construction in (32b) is contracted from the double verb construction in (32a).

9 The Chinese equivalent has been discussed under different frameworks by various authors, such as Poh Ean (1996), Shyu (2004), Yang and Wu (2019). A similar phenomenon can be found in Breton dialects (Glottolog: bret1244). The single verb construction is shortened from the double verb construction. Examples with verb doubling in Quimperl Breton can be alternatively expressed by a single verb construction in Standard Breton without any semantic difference, see (31). Standard Breton uses the expletive clitic bez' to replace the full-form of the fronted verb. The function of bez' 'expl' is to avoid the initial position of the inflected verb.

a. Quimperl Breton

\begin{tabular}{|c|c|c|c|c|c|}
\hline Mont & $a$ & yan & $d^{\prime}$ & $a r$ & jardin \\
\hline go & $\mathrm{r}$ & go.1sg & at & the & garden \\
\hline \multicolumn{6}{|c|}{ 'I am going into the garden.' (Jouitteau 2012: 136} \\
\hline \multicolumn{6}{|c|}{ Standard Breton } \\
\hline Bez' & $e z$ & an & $d^{\prime}$ & ar & jardin \\
\hline expl & $\mathrm{r}$ & go.1sg & at & the & garden \\
\hline
\end{tabular}




$\begin{array}{lllll}\text { a. 我 睡 } & \text { 也/都 } & \text { 没 } & \text { 睡 } \\ \text { wǒ shui yě/dōu } & \text { méi } & \text { shui } \\ \text { 1sG sleep also/all } & \text { did.not } & \text { sleep } \\ \text { 'I did not even sleep.' } & & \\ \text { b. } & \text { 我 也/都 } \quad \text { 没 } & \text { 睡 } & \\ & \text { wǒ yě/dōu méi } & \text { shui } & \\ \text { 1sG also/all did.not } & \text { sleep } & \\ & \text { 'I did not even sleep.' }\end{array}$

The simplification from an original double verb construction to a single verb construction preserving the clitic, like the Mandarin case, can also be the case of Siyuewu Khroskyabs.

The same kind of verb doubling is attested in Khroskyabs, the example with the prefix do- (Example 23, with the simplified version reproduced in 33b) has also an equivalent with the enclitic, without semantic differences, as shown in (33a).
a. $\quad s \eta \hat{\partial}=d \boldsymbol{\partial}$
kə-ma-sy-ón
sleep $_{1}=$ even $\quad$ PST-NEG-Sleep 2 -1sG
'I didn't even sleep.'
b. ka-ma-da-sy-ón
PST-NEG-even-sleep 2 -1SG
'I didn't even sleep.'

Like Mandarin, it is plausible to assume that (33b) is contracted from (33a) with the disappearance of the first verb. However, the contraction cannot be made as directly as the case of Chinese, as 也 yě 'also' and 都 dōu 'all' are not clitics, they do not need a host. The morpheme $=d \partial$ in Siyuewu Khroskyabs has to depend on a host, therefore, one needs to explain why it ended up in the modern position as in (33b).

When the Stem 1 verb, attached to the enclitic $=d \partial$, drops, the enclitic loses its host and needs to be reassigned after a new host without changing the meaning. It cannot be relocated after the verb stem, since kə-mə-s $\eta$-ó $\eta=d \partial$ (PST-NEG-Sleep ${ }_{2}$ $1 \mathrm{sG}=$ even) would have a different meaning, namely 'even if I did not sleep'. The most economic solution is moving to the nearest position both morphologically available and semantically pertinent, and this position turns out to be the closest position in the preverbal chain to the verb stem, resulting in the modern kə-mə-də-sy-ó $\eta$ (PST-NEG-even-sleep ${ }_{2}$-1sG) 'I didn’t even sleep'.

The pathway is illustrated in (34), showing the reassignment of the enclitic $=d \partial$ 'even' and its reanalysis into a prefix. The Khroskyabs inflectional chain is to be considered as having orignated from an old preverb-like or proclitic complex, led by orientational markers, that is, orientational markers were once an independent category of stems, serving as hosts of enclitics.This preverbal stem allows for an 
addition of external elements, and in later stages, it became fixed before the verb stem, and eventually formed a verbal complex with it.

$$
\begin{aligned}
& \text { I } \quad[\text { Verb }]=d a[\text { PREVERB }]=[\text { Verb }] \quad \text { Dropping of first verb } \\
& \text { II } \quad *=d \partial[\text { PREVERB] }]=[\text { Verb] Relocation of enclitic } \\
& \text { III } *[\text { PREVERB }]=d \partial=[\text { Verb] } \quad \text { Integration as prefix } \\
& \text { IV. [PREVERB-də]-[Verb] }
\end{aligned}
$$

The pathway is illustrated in a concrete manner in (35).

$$
\begin{aligned}
& \text { I } s \eta \hat{\partial}=\boldsymbol{d a} k \partial=m \partial=s \eta-o ́ \eta
\end{aligned}
$$

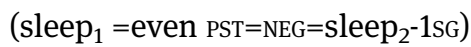

$$
\begin{aligned}
& \text { II }=\boldsymbol{d} \boldsymbol{\partial} \mathrm{k} \boldsymbol{\partial}=\mathrm{m} \boldsymbol{\partial}=\boldsymbol{s} \eta \text {-ó } \eta \\
& \text { (=even } \mathrm{PST}=\mathrm{NEG}=\text { sleep }_{2}-1 \mathrm{sG} \text { ) } \\
& \text { III } k \partial=m \boldsymbol{\partial}=\boldsymbol{d} \boldsymbol{\partial}=s \eta \text {-ó } \eta \\
& \text { (PST=NEG=even=sleep }{ }_{2}-1 \mathrm{sG} \text { ) } \\
& \text { IV kə-ma-da-sy-ón } \\
& \text { (PST-NEG-even-sleep } 2 \text {-1sG) }
\end{aligned}
$$

The pathway proposed here is not typologically ungrounded. The change from a preverb chain to a prefix chain is comparable to the evolution of preverbs in Germanic languages, where independent preverbs first evolved into the left member of verbal compounds, and then into prefixes, and finally dropped in some of the daughter languages (Booij and van Kemenade 2003: 4). In other IndoEuropean languages, such as Vedic Sanskrit (Glottolog: sans1269) and Florentine Italian, the preverbal elements allow integration of new morphemes, behaving similarly to Khroskyabs. Vedic Sanskrit exhibited tmesis, a phenomenon where other elements could be inserted between a preverb and a verb. As is shown in (36), a nominal phrase is placed between the preverb '́a 'to' and the verb asadat (sit.down:AOR:3sG.ACT) 'he has sat down'. Tmesis became much less common in later stages of the evolution of Sanskrit, and preverbs gradually became verbal prefixes, thus, integrated to the verb stem (Kulikov 2012: 725). The attested historical process in Sanskrit is very close to the pathway hypothesised for Khroskyabs.

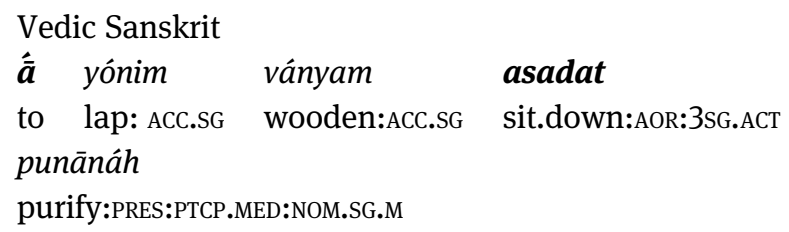


In Florentine of the thirteenth century, a new clitic ne 'thence' emerged from Latin inde 'thence', and is attached directly after the pre-established clitic chain, which included indirect object, direct object and locative clitics (Maiden 2013: 174-175). As Maiden (2013: 175) states explicitly, the collocation of $n e$ at the end of the clitic chain reflects its relatively late integration, which is also the case with Khroskyabs $=d \partial$ 'even'. The Florentine clitic order is illustrated in (37) (Nicol 2005: 154).

$$
\begin{aligned}
& \text { Florentine clitic order } \\
& l o, l a, l i, l e=l i, l e=m i=v i=t i=c i=s i=n e
\end{aligned}
$$

In some Australian languages, old preverbs, which once were a separate word class, became adjacent to the inflecting verb with a fixed order, forming a verbal complex (McGregor 2002: 339-351; Schultze-Berndt 2003: 158). An example is shown in (38). The original preverb gárd 'hit' is synchronically inseparable from the verbal complex.

(38) Gooniyandi (Glottolog: goon1238)

gárd + binggúni

hit + FUT:2PL:3PL:hit

'You will hit them.' (McGregor 1990: 200; Schultze-Berndt 2003: 159)

Proto-Mirndi (Glottolog: mirn1241) developed a polysynthetic verbal structure combining two originally separate grammatical words, the pronominal complex and the verbal complex, by transforming clitics and particles into prefixes. Such a change gave rise to the modern inflectional system of Mirndi (Osgarby 2018).

Our hypothesis on the integration of $d \partial$ - 'even' shows that, at the time of its integration, the inflectional chain as a whole was only loosely attached to the verb stem. The inflectional chain behaved like a preverb, although its internal elements were more tightly attached to each other, otherwise we would expect * $k \partial-d \partial-m \partial-s \eta$ ó (PST-even-NEG-sleep2-1sG). It seems that the inflectional chain was a sequence of grammatical adjuncts in Proto-Khroskyabs and was not grammaticalised as a series of prefixes as it is today. Therefore the inflectional chain was probably a grammatical word that was separate from the verb.

\subsection{Integration of 62 - ' $Q$ '}

Before postulating the evolutionary pathway, we need to explain the direction of the derivation. Just like with $d \partial$ - 'even', I assume that the enclitic $=6 \partial \gamma$ ' $\mathrm{Q}$ ' is original, and the prefix is derived. Apart from the typological reasons presented in Section 5.3, the cognate of $=6 \partial \gamma$ is attested in Japhug, appearing as $6 i$ ' $Q$ '. This marker is only attested as a sentence final particle, and never as a prefix, as shown 
in (5.4). Therefore, the prefix 6ə- in Khroskyabs must be more recent than the enclitic $=62 \gamma$.

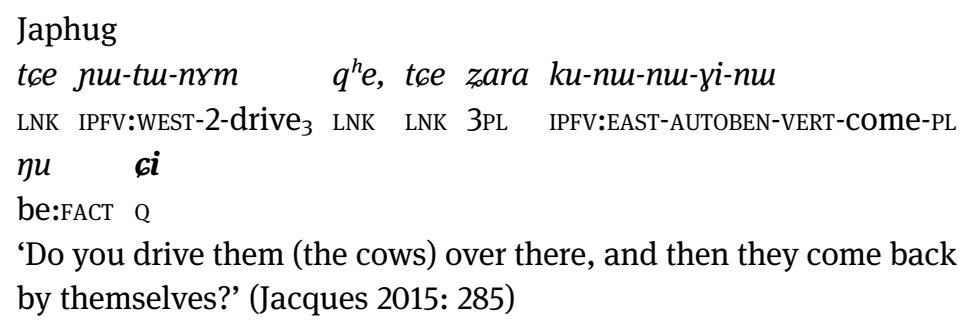

The example in (30) (Section 5.2) presents a familiar situation regarding the case of $d \partial$ - 'even', analysed in Section 5.3: the same verb appears twice in the construction, with the first one being marked by the enclitic under analysis.

This similarity leads us to put forward a hypothesis of the same sort. Given the semantic likeness and the fact that it is fossilised and relatively rarely attested, the construction with the enclitic, gradually declining in competition with the prefixed construction, is very likely to be the intermediate stage of the change from the enclitic $=62 y$ ' $Q$ ' to 62 - 'Q'.

In the beginning, the first instance of the verb dropped to avoid repetition, leaving the enclitic $=6$ zy without host. Then, the isolated enclitic was to move to the nearest position both morphologically available and semantically pertinent, that is, the end of the old preverbal chain. Because there was a maximality constraint in that period (see Section 4.1), the preverbal chain would not allow a sequence of three inflectional morphemes in a row, the negative marker had to cede its position to the question marker. Having become more grammaticalised, the phonological form 6 zy was reduced to 6 (phonological reduction is common in grammaticalisation, see Bybee et al. 1994: 19-21). The pathway is illustrated in (40). The analytic version with $=62 \gamma$ ' $\mathrm{Q}$ ' and NEG is rarely attested compared to the fully productive prefixed version with 62 - 'Q', the prefixed version has practically completely replaced the analytic one. Note that in this stage, the prefix 62 - is the newest prefix in the chain, occupying the last position: other prefixes after $6 \partial$ - (such as $r \hat{\partial}$ 'SEN', $z \hat{\partial}$ 'COND' and $d \partial$ - 'even') were not yet integrated in the chain.

$$
\begin{aligned}
& \text { I [PREVERB] }-[\text { Verb] }=6 \text { ay [PREVERB }=\text { NEG] }]=[\text { Verb] Dropping of first verb } \\
& \text { II }{ }^{*}=6 \partial \gamma[\text { PREVERB }=\mathrm{NEG}]=[\text { Verb] Relocation of enclitic } \\
& \text { III * }[\text { PREVERB }=\text { NEG }]=6 \partial y=[\text { Verb] Dropping of negative } m \partial- \\
& \text { IV * }[\text { PREVERB }]=6 \partial \gamma=[\text { Verb] Integration as prefix } \\
& \mathrm{V} \text { [PREVERB-6ə]-[Verb] }
\end{aligned}
$$

The pathway is illustrated with a concrete example in (41). 


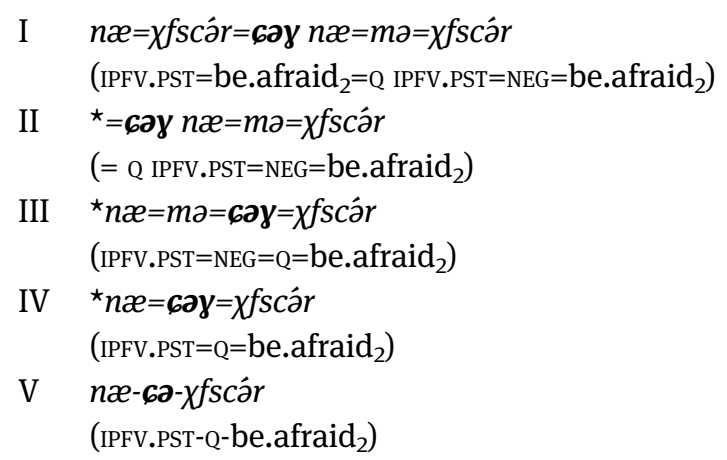

In other Trans-Himalayan languages, the omission of the negative marker in polar questions is not rare, especially in Lolo-Burmese (Glottolog: lolo1265), where [Verb-NEG-Verb] and [Verb-Verb] interrogatives coexist (Luo 2016: 73-74). As for Sinitic languages, a recent account on the evolution of [Verb-Verb] interrogative in a Yue dialect spoken in Huaiji (Glottolog: guin1237) shows that the origin of this construction is [Verb-NEG-Verb], and that the two constructions are in complementary distribution (Huang and Lin 2018). Although the mechanism of the omission of negative in Lolo-Burmese and in Yue is different from that in Khroskyabs, and yields different results, it shows that polar questions with a negative marker can evolve into a simplified version without negation.

\subsection{An alternative hypothesis}

The hypothesis on the integration of $d \partial$ - 'even' and 62 - 'Q' proposed in Sections 5.3 and 5.4 involves the disappearance of the first verb in the double verb construction as an initial step, and then, the reassignment of the hostless enclitic to the remaining part of the construction. However, in this section, I propose an alternative hypothesis in which the two major steps are reversed.

According to the description in Sections 5.1 and 5.2, it can be assumed that the enclitics $=d \partial$ 'also, even' and =6əy ' $Q$ ', in an intermediate stage, became ditropic clitics (Cysouw 2005), which semantically have scope following the element, rather than its morphological host. This resulted in the fact that they could either be attached to the first verb in the double verb construction, or to the second verb. When they were attached to the second verb, moving to the closest position available, the first verb became isolated and semantically useless, and finally dropped. The pathway therefore goes as follows. See (42). 


$$
\begin{aligned}
& \text { I [Verb]=CLITIC[PREVERB] }=[\text { Verb] Ditropicalisation } \\
& \text { II } \quad * \text { [Verb] CLITIC } \rightarrow \text { [PREVERB] }]=[\text { Verb] } \quad \text { Reassignment of enclitic } \\
& \text { III *[Verb] [PREVERB] }=\text { CLITIC }=[\text { Verb] } \quad \text { Dropping of first verb } \\
& \text { IV [PREVERB-CLITIC]-[Verb] }
\end{aligned}
$$

The pathway is illustrated with the case of $d \partial$ - 'even' in (43).

$$
\begin{aligned}
& \text { (43) I } s \eta \hat{\partial}=\boldsymbol{d a} k \partial=m \partial=s \eta-o ́ \eta
\end{aligned}
$$

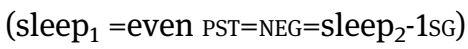

$$
\begin{aligned}
& \text { II } \quad{ }^{\star} s \eta \hat{\partial} \boldsymbol{d} \boldsymbol{\partial} \rightarrow k \partial=m \partial=s \eta \text {-ó } \eta
\end{aligned}
$$

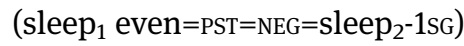

$$
\begin{aligned}
& \text { III * } s \eta \hat{\partial} k \partial=m \partial=\boldsymbol{d} \boldsymbol{\partial}=s \eta \text {-ó } \eta \\
& \left(\text { sleep }_{1} \text { PST=NEG=even=sleep }{ }_{2}-1 \mathrm{sG}\right) \\
& \text { IV ka-ma-do-sy-ón } \\
& \text { (PST-NEG-even-sleep } 2 \text {-1sG) }
\end{aligned}
$$

This alternative hypothesis and the main hypothesis are not in contradiction in that both suggest that the enclitics do not undergo a radical and abrupt change from a postposed morpheme to a preposed morpheme, instead, they always kept their enclitic nature before being reanalysed as prefixes. It is however not easy to decide which hypothesis is more plausible unless we find new evidence from Khroskyabs dialects or neighbouring languages.

\section{Discussion and conclusion}

Typological rarity can arise through different mechanisms even in the same family or branch. Jacques (2013) suggests that the grammaticalisation of some Japhug prefixes is not related to basic word order, nor is there a need for a historical VO stage. Rather, those prefixes are evolved from rare and marginal constructions. The Japhug case can be compared to Comrie's (1980: 89-93) analysis of Mongolic languages (Glottolog: mong1329) which shows us affix order is likely to be established through atypical word order. The case of the prefixes $d \partial$ - 'even' and $6 \partial$ 'Q' demonstrate two scenarios. Even though they are both from similar reduplicated constructions, $d \partial$ - 'even' evolved from a synchronically common construction with $=d \partial$ 'also, even', while $6 \partial$ - 'Q' evolved from a synchronically marginal construction, corresponding to the Comrie's suggestion.

The story of the inflectional chain in Khroskyabs seems paradoxical from a typological point of view at first sight. Khroskyabs betrays two general tendencies observed in the world's languages. On the one hand, while the universal tendency 
prefers suffixes, Khroskyabs has developed a complex chain of prefixes; on the other, the prefixes in inner slots are surprisingly more recent than the ones in outer slots, which is once more against the general typology.

If we take a closer look at the inflectional chain, we will find that the unusual structure of the inflectional chain came into being through a series a straightforward processes. We have shown that the enclitics, $=d \partial$ 'also' and $=6 \partial \gamma$ ' $\mathrm{Q}$ ', remained their nature of being postposed while attaching to the then established inflectional chain after their original hosts disappeared.

In the main hypothesis (Sections 5.3 and 5.4), the enclitics originally remained enclitics but changed their host, before being eventually integrated in the prefixal chain. In the alternative hypothesis (Section 5.5), the enclitics underwent ditropicalisation in order to be morphologically attached to the verb stem.

We can see that in both hypotheses, the enclitics stayed what they were, with the only difference being that they changed their hosts, before becoming prefixes, when the chain began to form a phonological unity with the verb stem and stopped receiving new morphemes. By obeying their own rule, they managed to "betray" the general tendencies.

The Khroskyabs case can be compared with that of Coptic (Grossman and Polis 2015, 2018), whose history is better attested. In Coptic, a large number of original suffixes turned into prefixes. It is shown that the percentage of prefixes increased dramatically from Earlier Egyption to Modern Coptic. However, like Khroskyabs, the Coptic "betrayal" seems also to be "paddling along with language change (quoting the title of Grossman and Polis 2018)". For instance, the subject person prefixes in Coptic were once suffixes attached to verbs, post-stem TAM markers or valency-changing affixes. After a new category of preverbal subject pronouns occurred in a later stage, the original person suffixes turned out to be more frequently used with these pronouns, and finally turned into prefixes. Like Khroskyabs, the change of hosts provided the environment needed for the emergence of person prefixes.

The goal of the present paper is to draw the attention of scholars studying the languages of the region, mostly underdocumented yet with complex morphology (inside or outside Gyalrongic), to the historical and comparative study of affix order of individual languages. Other languages may present similar or completely different pathways towards their current appearances, which, in either case, will be historically and typologically useful. 


\section{Abbreviations}

\begin{tabular}{|c|c|}
\hline$A B L$ & ablative \\
\hline $\mathrm{ACC}$ & accusative \\
\hline ACT & active \\
\hline$A D V$ & adverbialiser \\
\hline ALL & allative \\
\hline$A M$ & associated motion \\
\hline AMB & ambulative \\
\hline AOR & aorist \\
\hline ASSRT & assertive \\
\hline ATT & attenuative \\
\hline AUTOBEN & autobenefactive \\
\hline CAUS & causative \\
\hline CISLOC & cislocative \\
\hline $\mathrm{CL}$ & classifier \\
\hline COM & comitative \\
\hline COND & conditional \\
\hline CONJ & conjunction \\
\hline COP & copula \\
\hline CVB & converb \\
\hline DAT & dative \\
\hline DEF & definite \\
\hline DEM & demonstrative \\
\hline DENOM & denominal \\
\hline DIR & directional \\
\hline DU & dual \\
\hline DUB & dubitative \\
\hline ERG & ergative \\
\hline EVD & evidential \\
\hline EXPL & expletive \\
\hline FOC & focus \\
\hline FUT & future \\
\hline GEN & genitive \\
\hline GN & generic \\
\hline HYP & hypothetic \\
\hline IFR & inferential \\
\hline IMP & imperative \\
\hline IND & indicative \\
\hline INF & infinitive \\
\hline INSTR & instrumental \\
\hline INTERJ & interjection \\
\hline INTR & intransitive \\
\hline INV & inverse \\
\hline IPFV & imperfective \\
\hline IRR & irrealis \\
\hline
\end{tabular}




\begin{tabular}{|c|c|}
\hline JUSS & jussive \\
\hline LNK & linking word \\
\hline LOC & locative \\
\hline M & masculin \\
\hline MA & agent, marked form \\
\hline MED & middle \\
\hline NEG & negative \\
\hline NEGPT & past negative \\
\hline NMLZ & nominaliser \\
\hline NOM & nominative \\
\hline NPST & non-past \\
\hline NS & non-singular \\
\hline ORIEN & orientational prefix \\
\hline PART & particle \\
\hline PASS & passive \\
\hline PFV & perfective \\
\hline PL & plural \\
\hline PN & personal name (for names of unknown origins) \\
\hline POSB & possibility \\
\hline POSS & possessive \\
\hline PRES & present \\
\hline PROG & progressive \\
\hline PRON.REFL & reflexive pronoun \\
\hline PRT & preterite \\
\hline PST & past \\
\hline PTCP & participle \\
\hline Q & interrogative \\
\hline R & pre-tense particle \\
\hline RECP & reciprocal \\
\hline REDUP & reduplication \\
\hline SEN & sensory \\
\hline SG & singular \\
\hline SUPERL & superlative \\
\hline TRANSLOC & translocative \\
\hline TOP & topicaliser \\
\hline VERT & vertative \\
\hline VOL & volitive \\
\hline
\end{tabular}

Acknowledgments: I would like to thank Guillaume Jacques, Eitan Grossman, Lin You-Jing, Zhang Shuya, Angela Terrill and the three anonymous reviewers for their very useful comments and suggestions. All faults are mine.

Research funding: I have received funding from the European Research Council (ERC) under the European Unions Horizon 2020 research and innovation programme (Grant Agreement No. 715618, Computer-Assisted Language Comparison, https://digling.org/calc/). 


\section{References}

Ameka, Felix. 1992. Focus constructions in Ewe and Akan. MIT Working Papers in Linguistics 17. 1-25.

Baker, Mark. 1985. The mirror principle and morphosyntactic explanation. Linguistic Inquiry 16. 373-415.

Bickel, Balthasar, Goma Banjade, Martin Gaenszle, Elena Lieven, Netra Paudyal, Ichchha Purna Rai, Manoj Rai, Rai Novel Kishore \& Sabine Stoll. 2007. Free prefix ordering in Chintang. Language 83(1). 1-31.

Bickel, Balthasar \& Fernando Zúñiga. 2017. The 'word' in polysynthetic languages: phonological and syntactic challenges. In Michael Fortescue, Mithun Marianne \& Nicholas Evans (eds.), The Oxford handbook of polysynthesis. Oxford: Oxford University Press.

Bondaruk, Anna. 2009. Constraints on predicate clefting in Polish. In Zybatow Gerhild, Uwe Junghanns, Lenertová Denisa \& Petr Biskup (eds.), Studies in formal Slavic phonology, morphology, syntax, semantics and information structure: Proceedings of FDSL 7, Leipzig 2007, 65-79. Frankfurt am Main: Peter Lang.

Booij, Geert \& Ans van Kemenade. 2003. Preverbs: An introduction. In Booij Geert \& Jaap van Marle (eds.), Yearbook of morphology 2003, 145-177. Kluwer Academic Publishers.

Bybee, Joan L. 1985. Morphology: A study of the relation between meaning and form. Typological Studies in Language 9. John Benjamins Publishing Company.

Bybee, Joan L. 1994. Productivity, regularity and fusion: How language use affects the lexicon. In Rajendra Singh \& Richard Desrochers (eds.), Trubetzkoy’s orphan: Proceedings of the Montreal roundtable “Morphonology: Contemporary responses", 247-269. Amsterdam/ Philadelphia: John Benjamins.

Bybee, Joan L., Revere D. Perkins \& William Pagliuca. 1994. The evolution of grammar: Tense, aspect and modality in the languages of the world. Chicago: University of Chicago Press.

Bybee, Joan L., William Pagliuca \& Revere D. Perkins. 1990. On the asymmetries in the affixation of grammatical material. In Croft William, Keith Denning \& Suzanne Kemmer (eds.), Studies in typology and diachrony for Joseph $\mathrm{H}$. Greenberg, 1-42. Amsterdam: Benjamins.

Comrie, Bernard. 1980. Morphology and word order reconstruction: Problems and prospects. In Fisiak Jacek (ed.), Historical morphology. Trends in Linguistics, Studies and Monographs, Vol. 17, 83-96. The Hague: Mouton.

Cysouw, Michael. 2005. Morphology in the wrong place: A survey of preposed enclitics. In Wolfgang U. Dressler, Kastovsky Dieter, Oskar E. Pfeiffer \& Franz Rainer (eds.), Morphology and its demarcations: Selected papers from the 11th Morphology meeting, Vienna, February 2004, 17-37. Amsterdam: John Benjamins.

Cysouw, Michael. 2009. The asymmetry of affixation. In Snippets (Special issue in honor of Manfred Krifka, ed. by Sigrid Beck and Hans-Martin Gärtner), Vol. 20, 10-14.

de Vaan, Michiel. 2008. Etymological dictionary of latin and the other italic languages. Leiden: Brill.

DeLancey, Scott. 1981. An interpretation of split ergativity. Language 57(3). 626-657.

DeLancey, Scott. 2015. Adjectival construction in Bodo and Tibeto-Burman. In Language and Culture in Northeast India and Beyond: Honor of Robbins Burling, (ed.) Mark Post, Stephen Morey, and Scott DeLancey, 41-56. Asia-Pacific Linguistics, College of Asia and the Pacific, The Australian National University.

Dixon, Robert M. W. 1977. A grammar of Yidiny. Cambridge: Cambridge University Press. 
Dixon, Robert M. W. \& Aikhenvald Alexandra. 2002. Word: a crosslinguistic typology. Cambridge: Cambridge University Press.

Dryer, Matthew S. 2013. Prefixing vs. suffixing in inflectional morphology. In Matthew S. Dryer \& Martin Haspelmath (eds.), The world Atlas of language structures online, Chapter 26. Munich: Max Planck Digital Library. http://wals.info/chapter/26 (accessed 25 March 2018).

Gates, Jesse P. forthcoming. Grammaire du stau de Mazur. Paris: Écoles des Hautes Études en Sciences Sociales dissertation.

Gates, Jesse P. ms. Argument indexation in Stau from a cross-dialectal perspective. https://www. academia.edu/35252736/Argument_indexation_in_Stau_from_a_cross-dialectal_ perspective (accessed 4 December 2019).

Givón, Talmy. 1979. On understanding grammar. New York: Academic Press.

Gong, Xun. 2014. Personal agreement system of Zbu rGyalrong (Ngyaltsu variety). Transactions of the Philological Society 112(1). 44-60.

Gong, Xun. 2018. Le rGyalrong zbu, une langue tibéto-birmane de Chine du Sud-ouest : une étude descriptive, typologique et comparative. Paris: Institut national des langues et civilation orientales dissertation.

Greenberg, Joseph H. 1957. Essays in linguistics. Chicago: University of Chicago Press.

Greenberg, Joseph H. 1963. Universals of language. Cambridge, MA: MIT Press.

Grossman, Eitan \& Stéphane Polis. 2015. Dispreferred structures through language change: The diachrony of affix ordering in Ancient Egyptian-Coptic. Paper presented at Verbs, verb phrases, and verbal categories, a workshop at the Hebrew University of Jerusalem, March 23, 2015.

Grossman, Eitan \& Stéphane Polis. 2018. Swimming against the typological tide or paddling along with language change? Dispreferred structures and diachronic biases in affix ordering. Journal of Historical Linguistics 8(3). 388-443.

Hall, Christopher. 1988. Integrating diachronic and processing principles in explaining the suffixing preference. In John A. Hawkins (ed.), Explaining language universals, 321-349. Oxford: Blackwell.

Haspelmath, Martin. 1993. The diachronic externalization of inflection. Linguistics 31(2). 279-309.

Haspelmath, Martin. 2011. The indeterminacy of word segmentation and the nature of morphology and syntax. Folia Linguistica 45(1). 31-80.

Haspelmath, Martin. 2018. The last word on polysynthesis: A review article. Linguistic Typology 22(2). 307-326.

Hawkins, John A. \& Anne Cutler. 1988. Psycholinguistic factors in morphological asymmetry. In John A. Hawkins (ed.), Explaining language universals, 280-317. Cambridge: Cambridge University Press.

Hein, Johannes. 2017. Doubling and do-support in verbal fronting: Towards a typology of repair operations. Glossa: A Journal of General Linguistics 2(1). 1-36.

Heine, Bernd \& Tania Kuteva. 2002. World lexicon of grammaticalization. Cambridge: Cambridge University Press.

Hildebrandt, Kristine. A. 2015. The prosodic word. In John R. Taylor (ed.), The Oxford handbook of the word, 221-245. Oxford: Oxford University Press.

Himmelmann, Nikolaus P. 2014. Asymmetries in the prosodic phrasing of function words: Another look at the suffixing preference. Language 90(4). 927-960.

Hohenberger, Annette. 2007. The possible range of variation between sign languages : Universal Grammar, modality, and typological aspects. In Perniss Pamela, Pfau Roland \& 
Markus Steinbach (eds.), Visible variation: Comparative studies on sign language structure, 341-383. Berlin: Mouton de Gruyter.

Hoijer, Harry. 1971. Athapaskan morphology. In Jesse Sawyer (ed.), Encyclopedia of Chinese Language and Linguistics. Berkeley: University of California.

Honkasalo, Sami. 2018. System of Negation in Geshiza. Paper presented at Syntax of the World's Languages VIII, September 2018.

Hopper, Paul. 1991. On some principles of grammaticization. In Traugott Elizabeth Closs \&

Bernd Heine (eds.), Approaches to grammaticalization, Vol. 1, 17-35. Amsterdam/

Philadelphia: John Benjamins.

Hopper, Paul \& Elizabeth Closs Traugott. 2003. Grammaticalization, 2nd ed. Cambridge:

Cambridge University Press.

Huang, Bufan. 2007. Lawurongyu yanjiu. Beijing: Nationalities Press [Study on the Lavrung language].

Huang, Yixin \& Huayong Lin. 2018. Huaiji Xiafang Yueyu de chongdie yiwenju jiqi tanyuan -- yu Huaijibiao, Shunde Yueyu xiang lianxi 怀集下坊粤语的重叠式疑问句及其探源一一与怀集标 话、顺德粤语相联系 [The origin of reduplicated interrogatives in the Yue dialect of Huaiji Xiafang: compared to the Biao language of Huaijin and the Yue dialect of Shunde]. Essays on Linguistics 57. 351-393.

Hyman, Larry M. 2006. Word-prosodic typology. Phonology 23. 225-257.

Inkelas, Sharon. 2016. Affix ordering in optimal construction morphology. In Siddiqi Daniel \& Heidi Harley (eds.), Morphological metatheory, 479-511. Amsterdam/Philadelphia: John Benjamins.

Jacques, Guillaume. 2010a. The inverse in Japhug rGyalrong. Language and Linguistics 11(1). 127-157.

Jacques, Guillaume. 2010b. The three sisters. http://lacito.vjf.cnrs.fr/pangloss/resource/crdoJYA_TARURNWS_SOUND\&crdo-JYA_TARURNWS (accessed 26 March 2018).

Jacques, Guillaume. 2013. Harmonization and disharmonization of affix ordering and basic word order. Linguistic Typology 17. 187-215.

Jacques, Guillaume. 2015. The spontaneous-autobenefactive prefix in Japhug rGyalrong. Linguistics of the Tibeto-Burman Area 38(2). 271-291. Manuscript.

Jacques, Guillaume. ms. A grammar of Japhug.

Jacques, Guillaume, Anton Antonov, Yunfan Lai \& Nima Lobzang. 2014. Person marking in Stau. Himalayan Linguistics 13(2). 83-93.

Jacques, Guillaume, Yunfan Lai, Anton Antonov \& Lobsang Nima. 2017. Stau (Ergong, Horpa). In Thurgood Graham \& Randy LaPolla (eds.), The Sino-Tibetan languages, 2nd ed., 597-613. Abingdon and New York: Routledge.

Jouitteau, Mélanie. 2012. Verb doubling in Breton and Gungbe: Obligatory exponence at the sentence level. In Aboh 0. Enoch, Norval Smith \& Anne Zribi-Hertz (eds.), The morphosyntax of reiteration in Creole and non-Creole languages, 135-174. Amsterdam: John Benjamins.

Kim, Yuni. 2010. Phonological and morphological conditions on affix order in Huave. Morphology 20. 133-163.

König, Ekkehard. 1991. The meaning of focus particles: A comparative perspective. London: Routledge.

Kulikov, Leonid I. 2012. Vedic preverbs as markers of valency-changing derivations: Transitivity and objecthood in Indo-European (evidence from Old Indo-Aryan). Studies in Language 36(4). 721-746. 
Lai, Yunfan. 2015. The Person agreement system of Wobzi Lavrung (rGyalrongic, Tibeto-Burman). Transactions of the Philological Society 113(3). 271-285.

Lai, Yunfan. 2017. Grammaire du khroskyabs de wobzi. Paris: Université Paris 3 - Sorbonne Nouvelle dissertation.

Lai, Yunfan. 2018. Rethinking the orientational prefixes in rGyalrongic languages: The case of Siyuewu Khroskyabs. In Paper presented at the 51th International conference on Sino-Tibetan languages and linguistics, 25-28 September.

Lai, Yunfan. forthcoming. The historical development of inverse marking in Khroskyabs: Evidence from two modern varieties: Siyuewu and Wobzi. Bulletin of the School of Oriental and African Studies.

Lai, Yunfan, Xun Gong, Jesse P. Gates, \& Guillaume Jacques. forthcoming. Tangut as a West rGyalrongic language. Folia Linguistica Historica.

Lehmann, Christian. 2015. Thoughts on grammaticalization. Berlin: Language Science Press.

Li, Fanwen. 1997. Xia-Han zidian 夏漢字典 [Tangut-Chinese dictionary]. Beijing: China Social Sciences Press (李範文).

Luo, Tianhua. 2016. Interrogative strategies: An areal typology of the languages of China. Amsterdam/Philadelphia: John Benjamins.

Maiden, Martin. 2013. A linguistic history of Italian. London and New York: Routledge.

McGregor, William B. 1990. A functional grammar of Gooniyandi. Amsterdam: Benjamins.

McGregor, William B. 2002. Verb classification in Australian languages. Berlin and New York: Mouton de Gruyter.

Miestamo, Matti. 2005. Standard negation: The negation of declarative verbal main clauses in a typological perspective. Berlin: Mouton de Gruyter.

Miestamo, Matti \& Johan van der Auwera. 2007. Negative declaratives and negative imperatives: Similarities and differences. In Ammann Andreas (ed.), Linguistics festival, 59-77. Bochum: Brockmeyer.

Mithun, Marianne. 2000. The reordering of morphemes. In Gildea Spike (ed.), Reconstructing grammar, comparative linguistics and gramamticalization, 231-258. Amsterdam: Benjamins.

Mithun, Marianne. 2003. Why prefixes? Acta Linguistica Hungarica 50(1-2). 155-135.

Mithun, Marianne. 2016. Affix ordering: Motivation and interpretation. In Hippisley Andrew \& Gregory Stump (eds.), The Cambridge handbook of morphology, 149-185. Cambridge: Cambridge University Press.

Nicol, Fabrice. 2005. Romance clitic clusters: On diachronic changes and cross-linguistic contrasts. In Heggie Lorie \& Francisco Ordóñez (eds.), Clitic and affix combinations: Theoretical perspectives, 141-197. Amsterdam: John Benjamins.

Norde, Muriel. 2011. Degrammaticalization. In Narrog Heiko \& Bernd Heine (eds.), The Oxford handbook of grammaticalization, 475-487. Oxford: Oxford University Press.

Osgarby, David. 2018. Reconstructing Proto-Mirndi verbal morphology: From particles and clitics to prefixes. Australian Journal of Linguistics 38(2). 223-292.

Parkvall, Mikael. 2000. Out of Africa: African influences in Atlantic Creoles. London: Battlebridge.

Partridge, Eric. 2006. Origins: A short etymological dictionary of Modern English. London and New York: Routledge.

Poh Ean, Agnes. 1996. The deletability of "Lian" in the construction of "Lian...Ye/Dou" in Mandarin Chinese. Université Paris VII - Denis Diderot Master's thesis.

Post, Mark. 2015. Sino-Tibetan negation and the case of Galo: Explaining a distributional oddity in diachronic terms. Language and Linguistics 16(3). 431-464. 
Reynolds, Robert. 2013. Out of order?: Russian prefixes, complexity-based ordering and acyclicity. University of Pennsylvania Working Papers in Linguistics 19(1). 158-168.

Sapir, Edward. 1921. Language, an introduction to the study of speech. New York: Brace.

Schultze-Berndt, Eva. 2003. Preverbs as an open word class in Northern Australian languages: synchronic and diachronic correlates. In Booij Geert \& Jaap van Marle (eds.), Yearbook of morphology 2003, 145-177. Kluwer Academic Publishers.

Shyu, Shu-ing. 2004. (A)symmetries between Mandarin Chinese Lian-dou and Shenzhi. Journal of Chinese Linguistics 32(1). 71-128.

Sun, Jackson T.-S. 2000. Parallelisms in the verb morphology of Sidaba rGyalrong and Lavrung in rGyalrongic. Language and Linguistics 1(1). 161-190.

Sun, Jackson T.-S. 2003. Caodeng rGyalrong. In Thurgood Graham \& Randy LaPolla (eds.), The Sino-Tibetan languages, 490-502. London: Routledge.

Sun, Jackson T.-S. 2007. The irrealis category in rGyalrong. Language \& Linguistics 8(3). 797-819.

Sun, Jackson T.-S. 2014. Sino-Tibetan: rGyalrong. In Lieber Rochelle \& Pavol Štekauer (eds.), The Oxford handbook of derivational morphology, 630-650. Oxford: Oxford University Press.

Sun, Jackson T.-S. \& Shi Danluo. 2002. Caodeng Jiarongyu yu rentong dengdi xiangguan de yufa xianxiang 草登嘉戎語與「認同等第」相關的語法現象 [Empathy Hierarchy in Caodeng rGyalrong grammar)]. Language and Linguistics 3(1). 79-99.

Vajda, Edward J. 2017. Polysynthesis in Ket. In Fortescue Michael, Mithun Marianne \& Nicholas Evans (eds.), The Oxford handbook of polysynthesis, 906-929. Oxford: Oxford University Press.

van der Auwera, Johan \& Ludo Lejeune. 2013. The prohibitive. In S Dryer Matthew \& Martin Haspelmath (eds.), World Atlas of linguistic structures online, Chapter 71. Leipzig: Max Planck Institute for Evolutionary Anthropology. http://wals.info/chapter/71 (accessed 25 March 2018).

Werner, Heinrich. 1997. Die ketische Sprache. Wiesbaden: Harrassowitz.

Yang, Xiaolong \& Yicheng Wu. 2019. A dynamic account of Lian ... dou in Chinese verb doubling cleft construction, Vol. 217, 24-44. Lingua.

Zhang, Shuya. 2016. La phonologie et la morphologie du dialecte de brag-dbar du rGyalrong situ. INALCO Master's thesis.

Zhang, Shuya. 2019. From proximate/obviative to number marking: Reanalysis of hierarchical indexation in rGyalrong languages. Journal of Chinese Linguistics 47(1). 125-150. 